\title{
Modulation of hepatic inflammation and energy-sensing pathways in the rat liver by high-fructose diet and chronic stress
}

\author{
Nataša Veličković ${ }^{\text {- Ana Teofilović }}{ }^{1}$. Dragana llić ${ }^{*}$ Ana Djordjevic ${ }^{1}$ - Danijela Vojnović Milutinović ${ }^{1}$. \\ Snježana Petrović ${ }^{2} \cdot$ Frederic Preitner $^{3} \cdot$ Luc Tappy $^{4} \cdot$ Gordana Matić $^{1}$
}

Received: 7 February 2018 / Accepted: 22 May 2018 / Published online: 29 May 2018

c) Springer-Verlag GmbH Germany, part of Springer Nature 2018

\begin{abstract}
Purpose High-fructose consumption and chronic stress are both associated with metabolic inflammation and insulin resistance. Recently, disturbed activity of energy sensor AMP-activated protein kinase (AMPK) was recognized as mediator between nutrient-induced stress and inflammation. Thus, we analyzed the effects of high-fructose diet, alone or in combination with chronic stress, on glucose homeostasis, inflammation and expression of energy sensing proteins in the rat liver. Methods In male Wistar rats exposed to 9-week 20\% fructose diet and/or 4-week chronic unpredictable stress we measured plasma and hepatic corticosterone level, indicators of glucose homeostasis and lipid metabolism, hepatic inflammation (pro- and anti-inflammatory cytokine levels, Toll-like receptor 4, NLRP3, activation of NFKB, JNK and ERK pathways) and levels of energy-sensing proteins AMPK, SIRT1 and peroxisome proliferator-activated receptor gamma coactivator-1 alpha (PGC- $1 \alpha)$.

Results High-fructose diet led to glucose intolerance, activation of NFKB and JNK pathways and increased intrahepatic IL-1 $\beta, T N F \alpha$ and inhibitory phosphorylation of insulin receptor substrate $1 \mathrm{on} \mathrm{Ser}^{307}$. It also decreased phospho-AMPK/ AMPK ratio and increased SIRT1 expression. Stress alone increased plasma and hepatic corticosterone but did not influence glucose tolerance, nor hepatic inflammatory or energy-sensing proteins. After the combined treatment, hepatic corticosterone was increased, glucose tolerance remained preserved, while hepatic inflammation was partially prevented despite decreased AMPK activity.

Conclusion High-fructose diet resulted in glucose intolerance, hepatic inflammation, decreased AMPK activity and reduced insulin sensitivity. Chronic stress alone did not exert such effects, but when applied together with high-fructose diet it could partially prevent fructose-induced inflammation, presumably due to increased hepatic glucocorticoids.
\end{abstract}

Keywords Inflammation $\cdot$ AMP-activated protein kinase $\cdot$ Dietary fructose $\cdot$ Stress $\cdot$ Rat liver

\section{Introduction}

Nataša Veličković

nvelickovic@ibiss.bg.ac.rs

1 Department of Biochemistry, Institute for Biological Research "Siniša Stanković", University of Belgrade, 142 Despot Stefan Blvd., Belgrade 11000, Serbia

2 Centre of Research Excellence in Nutrition and Metabolism, Institute for Medical Research, University of Belgrade, Tadeuša Košćuška 1, Belgrade 11129, Serbia

3 Mouse Metabolic Facility (MEF), Center for Integrative Genomics, University of Lausanne, 1015 Lausanne, Switzerland

4 Department of Physiology, University of Lausanne, UNIL-CHUV, Rue du Bugnon 7, 1005 Lausanne, Switzerland
Modern way of living, which combines consumption of energy-dense foods and psychosocial stress, is associated with health threats, such as metabolic syndrome, cardiovascular diseases and cancer. Fructose-fed rat is a model reproducing various aspects of metabolic syndrome, including hypertriglyceridemia, insulin resistance and hepatic steatosis [1]. Moreover, stress increases visceral adiposity and weight gain by changing eating patterns and shifting preference towards palatable foods high in fat and sugar [2]. However, the relationship between stress and obesity remains elusive, as some people lose weight when exposed to stress [3]. Both fructose- and stress-mediated metabolic disturbances are associated with 
low-grade chronic inflammation, characterized by activation of proinflammatory nuclear factor kappa B (NFkB), c-Jun N-terminal kinase 1 (JNK) and extracellular signalregulated kinase (ERK) signaling pathways and increased production of proinflammatory cytokines (tumor necrosis factor $\alpha(\mathrm{TNF} \alpha)$, interleukin (IL) $1 \beta$ and IL-6) [4]. Inflammatory response may in turn impair insulin signaling by increasing inhibitory phosphorylation of insulin receptor substrate 1 (IRS1) on serine residues [5]. Indeed, JNK phosphorylates IRS1 on $\mathrm{Ser}^{307}$ residue, which represents an early hallmark of tissue insulin resistance [6], while ERK promotes insulin resistance through phosphorylation of IRS1 on $\operatorname{Ser}^{612}$ [7].

AMP-activated protein kinase (AMPK), one of the principal cellular energy sensors, plays an important role in maintaining energy homeostasis through downregulation of ATP-consuming pathways and stimulation of ATP-producing pathways [8]. Impairment of hepatic AMPK activity is a key pathological event in the development of the insulin resistance and hepatic steatosis in the metabolic syndrome [9]. However, the new emerging role of AMPK signaling is in the regulation of metabolic inflammation [10]. Studies in both humans and experimental animals showed a negative association between diet-induced inflammation and AMPK activity [9]. Moreover, high-fat or high-fructose diet activates inflammation by suppressing AMPK pathway in the heart [11, 12]. In addition, glucocorticoid-induced changes in AMPK constitute a novel mechanism that could explain the deposition of lipids in visceral adipose and hepatic tissue.

Multiple studies have demonstrated that AMPK restrains inflammation through inhibition of $\mathrm{NFkB}$, a key regulator of innate immunity and inflammation [13, 14]. In unstimulated cells, NFKB is sequestered in the cytoplasm in an inactive complex with inhibitory protein $\kappa \mathrm{B}(\mathrm{I} \kappa \mathrm{B})$ and is activated by phosphorylation and degradation of IкB [15]. Since AMPK activity is decreased in obesity and metabolic syndrome, this could lead to derepression of proinflammatory stimuli associated with diet/obesity and appearance of a low-grade metabolic inflammation [16]. Inhibitory effects of AMPK on NFkB signaling are likely to be indirect and governed by downstream mediators, such as sirtuin 1 (SIRT1) and peroxisome proliferator-activated receptor gamma coactivator 1 alpha (PGC-1 $\alpha$ ) [16]. Indeed, SIRT1 deacetylates the RelA/ p65 subunit of NFKB complex that triggers the ubiquitination and degradation of $\mathrm{NF \kappa B}$ [17]. Increased activity of PGC- $1 \alpha$ could inhibit NFKB activity and proinflammatory response induced by TNF $\alpha$ in vascular cells [18]. Highfructose ingestion has been described to reduce [19] or to increase SIRT1 and PGC- $1 \alpha$ activities [20], and the effect of stress on SIRT1 activity is also still controversial [21]. Therefore, the dysregulation of energy sensing may link nutrient metabolism to inflammation and insulin resistance.
Only few studies have focused on the mechanisms underlying metabolic inflammation provoked by the interaction between a carbohydrate-enriched diet and stress [22, 23]. The aim of this study was to investigate the effects of highfructose diet and chronic unpredictable stress, separately or in combination, on glucose homeostasis and hepatic inflammation in the male Wistar rats, as well as to reveal whether these metabolic perturbations are linked with the alterations in energy-sensing proteins levels. The concentration of $20 \%$ fructose solution was chosen to resemble the consumption of fructose-sweetened beverages in human population [24], while chronic unpredictable stress protocol represents paradigm for everyday stress exposure in human life and consisted of psychological and physical stressors [25]. We examined the effect of fructose-enriched diet and/or chronic stress on the liver histology, the plasma and hepatic corticosterone level, parameters of glucose homeostasis (glucose tolerance, fasting glucose and insulin plasma values, phosphoenolpyruvate carboxykinase (PEPCK) mRNA and phosphorylation of IRS1 at $\mathrm{Ser}^{307}$ ) and lipid metabolism (plasma and hepatic triglyceride level and hepatic fatty acid composition). Hepatic inflammation was characterized by measuring the tissue level of pro- and anti-inflammatory cytokines, as well as by analyzing expression of proinflammatory factor NFKB and kinases JNK and ERK, Toll-like receptor-4 (TRL4) and Nod-like receptor protein 3 (NLRP3). In addition, the expression of main energy-sensing proteins AMPK, SIRT1 and PGC- $1 \alpha$ were examined in the liver of rats exposed to high dietary fructose, alone or in combination with stress.

\section{Materials and methods}

\section{Animals and treatment}

Experiments were conducted on 2.5-month-old Wistar male rats, bred in our laboratory. At the beginning of the 9-week experiment, rats were divided into four groups ( $n=9$ per group) and housed three per cage. Untreated control group (C) had free access to a standard chow diet (commercial food-Veterinary Institute, Subotica, Serbia) and drinking water [26]. The fructose-fed group (F) received high-fructose diet (20\% fructose in drinking water, API-PEK, Bečej, Serbia) and commercial food. The third, stress (S) group of animals was subjected to a modified version of the chronic unpredictable stress (CUS) protocol of Joels et al. [25] during the last 4 weeks of the treatment. The animals were successively exposed to one of the following daily stressors: forced swimming in cold water for $10 \mathrm{~min}$, physical restraint for $30 \mathrm{~min}$, cold room $\left(4{ }^{\circ} \mathrm{C}\right.$ ) for $50 \mathrm{~min}$, wet bedding for $4 \mathrm{~h}$, rocking cages for $1 \mathrm{~h}$ and cage tilt $\left(45^{\circ}\right)$ overnight. The time and type of 
daily stressors were randomly selected at the beginning of the treatment. The fourth group (SF) was exposed to both 9-week high-fructose diet and 4-week stress protocol. Free access to food was allowed to all the animals. Daily food and fluid intake were measured throughout the treatment, while body weight was recorded weekly. Total energy intake was expressed as $\mathrm{kJ}$ per day per animal and was calculated as previously reported [27]. The animals were maintained under a 12-h light-dark cycle (lights on at 7:00 a.m.) at $22{ }^{\circ} \mathrm{C}$ and constant humidity. The protocols were performed in compliance with Directive 2010/63/ EU on the protection of animals used for experimental and other scientific purposes and were approved by the Ethical Committee for the Use of Laboratory Animals of the Institute for Biological Research "Siniša Stanković", University of Belgrade (reference number 3-12/12).

\section{Blood plasma preparation, tissue collection, and determination of biochemical parameters}

After an overnight fast, animals were killed at light onset (7:00 AM) by decapitation with a guillotine (Harvard Apparatus, USA). Trunk blood was rapidly collected and the concentrations of glucose were measured by a MultiCare ${ }^{\circledR}$ glucometer, using MultiCare Glucose strips (Biochemical Systems International, Italia), while triglyceride concentrations in the blood were measured by MultiCare Triglycerides strips (Biochemical Systems International, Italia). Plasma was isolated by centrifugation at $1600 \times g$ for $10 \mathrm{~min}$ at $4{ }^{\circ} \mathrm{C}$ and then stored at $-20{ }^{\circ} \mathrm{C}$. The concentration of plasma insulin was determined by the RIA method, using rat insulin standards (INEP, Serbia). Assay sensitivity was $0.6 \mathrm{mIU} / \mathrm{L}$ and the intra-assay coefficient of variation was $5.24 \%$. Corticosterone was measured in the plasma and liver cytoplasmic extracts using the Corticosterone EIA kits (AC14F1 and AC-15F1, Immunodiagnostic Systems Ltd, UK, respectively) according to the manufacturer's instructions. Absorbance at $450 \mathrm{~nm}$ (reference $650 \mathrm{~nm}$ ) was measured spectrophotometrically (Multiskan Spectrum, Thermo, Finland). Corticosterone concentrations were determined using four parameter logistic (4PL) curve-fitting method (Prism, GraphPad Software) and given as $\mathrm{ng} / \mathrm{ml}$ or $\mathrm{ng} / \mathrm{mg}$ of protein. The assay sensitivity was $0.17 \mathrm{ng} / \mathrm{mL}$, while intra-assay and inter-assay CVs were 5.9 and $8.9 \%$, respectively. To validate the use of cytoplasmic extracts in the ELISA, a spike and recovery experiment was done with the known amount of the kit standard. A dilution series was performed comparing the spiked vs. the unspiked sample and the obtained recovery range was between 87 and $113 \%$.

After blood collection, the livers were perfused with cold $0.9 \% \mathrm{NaCl}$, carefully excised and frozen in liquid nitrogen. Tissues were kept in liquid nitrogen for protein isolation.

\section{Histological analysis of the liver}

Samples of liver tissue were fixed in $4 \%$ paraformaldehyde for $24 \mathrm{~h}$, dehydrated in an ethanol gradient, cleared in xylene and embedded in paraffin. Tissue blocks were sectioned at $5 \mu \mathrm{m}$ thickness and stained with hematoxylin and eosin. Microscopic analysis was carried out using a workstation comprising a microscope Leica DM RB Photo Microscope (Leica, Wetzlar, Germany) equipped with the Leica DFC320 digital camera (Leica, Wetzlar, Germany).

\section{Determination of hepatic triglycerides and fatty acid profile of total plasma and hepatic lipids}

Liver triglycerides were isolated from $100 \mathrm{mg}$ of liver tissue using a modified Folch method [28] and analyzed with Triglycerides Reagent (Code 12528, Biosystem) on the semi-automatic biochemistry analyzer Rayto 1904-C (Rayto, China).

For analysis of fatty acid profile, total plasma lipids were extracted by the method of Glaser et al. [29], while total hepatic lipid extracts were isolated from $\sim 500 \mathrm{mg}$ liver tissue by the method of Petrovic et al. [30]. Fatty acid composition of total lipids from plasma and liver was analyzed according to the protocol described by Petrovic et al. [30]. Individual fatty acid methyl esters in the samples were identified by comparing sample peak retention times with polyunsaturated fatty acid (PUFA)-2 standard mixture (Restek Co, Bellefonte, PA, USA). Fatty acid profiles were expressed as the percentage areas of total fatty acids. The $\Delta 9$ desaturase activity was estimated as the product-to-precursor ratio of 18:1/18:0 [30].

\section{Estimation of glucose tolerance}

Intraperitoneal glucose tolerance test (IPGTT) was performed 3 days before the end of the treatment. Food was removed the night before and fructose solution was temporarily replaced with water. A bolus of glucose was injected intraperitoneally $(2 \mathrm{~g} / \mathrm{kg})$. Blood was obtained from the tail, and the glucose level was measured at $0,30,60,90$ and $120 \mathrm{~min}$ after injection. The area under the glycemic curve over the course of the experiment (AUC glucose 0-120 min, $\mathrm{mmol} / \mathrm{L}$ vs. min) was calculated by the trapezoidal rule.

\section{Preparation of cytoplasmic, nuclear and whole cell extracts}

Frozen livers were weighed and homogenized with Janke-Kunkel ultraturrax (30 s/30 s pause/30 s) in 4 vol. $(\mathrm{w} / \mathrm{v})$ of ice-cold homogenization buffer $(20 \mathrm{mM}$ Tris- $\mathrm{HCl}$, pH 7.2, $10 \%$ glycerol, $50 \mathrm{mM} \mathrm{NaCl}, 1 \mathrm{mM}$ EDTA- $\mathrm{Na}_{2}$, $1 \mathrm{mM}$ EGTA-Na $2,2 \mathrm{mM}$ DTT, protease and phosphatase 
inhibitors). The homogenates were filtered through gauze and centrifuged $\left(2000 \times g, 15 \mathrm{~min}, 4{ }^{\circ} \mathrm{C}\right)$. The resulting supernatants were further processed to generate cytoplasmic fraction, while the pellets were used to obtain nuclear extracts, as previously published [27]. All steps were conducted at $4{ }^{\circ} \mathrm{C}$ and all samples were aliquoted and stored at $-70{ }^{\circ} \mathrm{C}$.

For preparation of whole cell extracts, tissues were homogenized with a glass-Teflon homogenizer in 5 vol. (w/v) of ice-cold RIPA buffer (50 mM Tris-HCl, $\mathrm{pH} 7.2$, $1 \mathrm{mM}$ EDTA-Na $\mathrm{Na}_{2}, 150 \mathrm{mM} \mathrm{NaCl}, 0.1 \%$ SDS, $1 \%$ Nonidet P-40, $0.5 \%$ sodium deoxycholate, 2 mM DTT, protease and phosphatase inhibitors) and homogenates were sonicated $(3 \times 5 \mathrm{~s}, 1 \mathrm{~A}, 50 / 60 \mathrm{~Hz})$. After $60 \mathrm{~min}$ of incubation on ice with continuous agitation and frequent vortexing, suspensions were centrifuged $\left(16,000 \times g, 20 \mathrm{~min}, 4{ }^{\circ} \mathrm{C}\right)$ and the resulting supernatants were aliquoted, stored at $-70^{\circ} \mathrm{C}$ and used as whole cell extracts.

Protein content of all cellular fractions was determined by the method of Spector [31] using bovine serum albumin as a standard.

\section{Cytokine immunoassays}

Levels of cytokines in the liver were determined by specific ELISA kit assay (Rat TNF $\alpha$ ELISA kit, \# 88-7340-88, eBioscience; rat IL-1 $\beta$ ELISA kit, DY501; rat IL-6 ELISA kit, DY506; rat IL-4 ELISA kit, DY504; rat IL-10 ELISA kit, DY522, all from R\&D Systems) [32]. Cytokine measurement was done in whole cell extracts from the livers isolated by previously published protocol [33]. In brief, $100 \mathrm{mg}$ of liver was homogenized in $10 \mathrm{vol}$. (w/v) of PBS buffer $\left(137 \mathrm{mM} \mathrm{NaCl}, 2.7 \mathrm{mM} \mathrm{KCl}, 10 \mathrm{mM} \mathrm{Na} 2 \mathrm{HPO}_{4}, 1.8 \mathrm{mM}\right.$ $\mathrm{KH}_{2} \mathrm{PO}_{4}, 0.5 \%$ Triton X-100 and protease inhibitors), then sonicated $3 \times 5 \mathrm{~s} / 30 \mathrm{~s}$ pause $(30 \mathrm{~Hz}$, pulse 0.5$)$. Homogenates were centrifuged at $12,000 \times g, 10 \mathrm{~min}, 4^{\circ} \mathrm{C}$, and the resulting supernatants were aliquoted and stored at $-70{ }^{\circ} \mathrm{C}$. The level of cytokines was measured in 96-well plates according to the manufacturer's instructions. Absorbance was read at 450 and $540 \mathrm{~nm}$ on the Multiskan Spectrum (Thermo Electron Corporation, Finland). Results were expressed as pg/ $\mathrm{mg}$ of protein.

\section{Western blot analysis}

After the samples were boiled in Laemmli's buffer, $40 \mu \mathrm{g}$ of cytosolic or whole cell extract, or $60 \mu \mathrm{g}$ of nuclear extract proteins was resolved on 7.5 or $10 \%$ SDS-polyacrylamide gels. The samples intended to be compared were always run on the same gel. Separated proteins were transferred to PVDF membranes (Immobilon-FL, Millipore). The blots were blocked by PBS containing $2 \%$ non-fat dry milk for $1 \mathrm{~h}$ at room temperature. After extensive washing (PBS containing $0.1 \%$ Tween 20 ), membranes were incubated overnight at $4{ }^{\circ} \mathrm{C}$ with the following anti-rabbit polyclonal antibodies: NFkB (p65 subunit) antibody (sc-372, 1:250), I $\mathrm{B} \alpha$ antibody (sc-371, 1:250), AMPK $\alpha$ 1/2 (sc-25792, 1:500), SIRT1 antibody (sc-15404, 1:250), JNK1/2 (sc-571, 1:500), all from Santa Cruz Biotechnology. Phospho-IкB $\alpha$ antibody $\left(\mathrm{Ser}^{32}\right)$ (\#2859, 1:1000), phospho-AMPK ( $\left.\mathrm{Thr}^{172}\right)$ (\#41885, 1:500), phospho-ERK1/2 $\left(\mathrm{Thr}^{202} / \mathrm{Tyr}^{204}\right)$ (\#9101, 1:250), ERK1/2 (\#9102, 1:1000), phospho-JNK1/2 (Thr ${ }^{183}$ / $\mathrm{Tyr}^{185}$ ) (\#9251S, 1:250) were all from Cell Signaling, while PGC-1 $\alpha$ (ab54481, 1:1000), NLRP3 (ab214185, 1:500) and phospho-IRS1 $\left(\mathrm{Ser}^{307}\right)$ antibodies (ab5599, 1:1000) were from Abcam. Anti- $\beta$-actin (ab-8227, Abcam, 1:10,000) and TATA box-binding protein (TBP, ab-22595, Abcam, 1:1000) were used as an equal loading control for cytosolic/whole cell and nuclear protein, respectively. Membranes were subsequently washed and incubated for $90 \mathrm{~min}$ with horseradish peroxidase-conjugated secondary antibodies (Thermo Scientific, 1:5000). The immunoreactive proteins were visualized by chemiluminescent (ECL) method and quantitative analysis was performed by ImageJ software (National Institute of Health, USA).

\section{RNA isolation and reverse transcription}

Total RNA was isolated from liver tissue using TRIzol ${ }^{\circledR}$ Reagent (AmBion, Life Technologies, Carlsbad, CA, USA) according to the manufacturer's instructions. Quantitative and qualitative evaluation of the isolated RNA was performed spectrophotometrically (OD 260/280 > 1.8 was considered satisfactory) and on $2 \%$ agarose gel. Prior to cDNA synthesis, DNA contamination was removed by DNAse I treatment (Fermentas, Burlington, ON, Canada). Reverse transcription was performed using a high-capacity cDNA Reverse Transcription Kit (Applied Biosystems, Foster City, CA, USA) according to the manufacturer's instructions. The cDNAs were stored at $-70{ }^{\circ} \mathrm{C}$ until use.

\section{Real-time PCR}

Quantification of glucocorticoid receptor (GR) and PEPCK gene expression in the liver was performed by TaqMan ${ }^{\circledR}$ real-time polymerase chain reaction (PCR). The following probe sets were used: GR (Rn00561369_m1*) and PEPCK (Rn01529014_m1*), all obtained from Applied Biosystems Assay-on Demand Gene Expression Products. $\beta$-Actin (Rn00667869_m1*) was used as internal control for quantitative normalization of cDNA. Real-time PCR was performed using the QuantStudio ${ }^{\mathrm{TM}}$ Real-Time PCR Systems as previously described [26]. The expression of TLR4 and AMPK genes was analyzed using Power SYBR ${ }^{\circledR}$ Green PCR Master Mix (Applied Biosystems) and specific primers (Metabion): TLR4 forward 5'-ATC ATC CAG GAA 
GGC TTC CA-3', reverse 5'-GCT AAG AAG GCG ATA CAA TTC- $3^{\prime}$ and AMPK $\alpha 1$ forward 5'-GGG ATC CAT CAG CAA CTA TCG-3', reverse 5'-TTC CTG GTC TTG GAG CTA CGT- $3^{\prime}$. Quantitative normalization of cDNA in each sample was performed using $\beta$-actin (forward $5^{\prime}$-CCC TGG CTC CTA GCA CCA T-3', reverse 5'-GAG CCA CCA ATC CAC ACA GA-3') as endogenous control. Real-time PCR was performed using QuantStudio ${ }^{\mathrm{TM}}$ Real-Time PCR Systems (Applied Biosystems, Foster City, CA, USA) as previously published [26]. Relative quantification of gene expression was examined using comparative $2^{-\Delta \Delta C_{\mathrm{t}}}$ method described by Livak and Schmittgen [34]. The results were analyzed by QuantStudio ${ }^{\mathrm{TM}}$ Design and Analysis v1.3.1 (Applied Biosystems, Foster City, CA, USA) with a confidence level of $95 \%(p \leq 0.05)$.

\section{Statistical analysis}

The data for physiological, biochemical and insulin sensitivity parameters, as well as ELISA, Western blot and real-time PCR data were given as means \pm SEM. The normality of the data was analyzed by Shapiro-Wilk test. Two-way ANOVA followed by Tukey post hoc test was used to evaluate the effects of fructose diet and stress, as well as their interaction on treated groups. Results were considered statistically significant at $p<0.05$. Statistical analyses were performed by STATISTICA 8.0. software (StatSoft, Inc., USA).

\section{Results}

\section{Effects of high-fructose diet and/or stress on energy intake, body composition and corticosterone level in male Wistar rats}

Fructose diet caused a significantly higher total energy intake $(37-44 \%)$ in both fructose and fructose + stress groups, as compared to untreated controls or rats exposed only to stress (Table $1, p<0.001$ for all comparisons). However, the increase in caloric intake was not translated into significant increase of either body weight or liver mass in fructose-fed rats, with the exception of a $26 \%$ increase in the liver-to-body weight ratio in the fructoseonly group compared to controls (Table $1, p<0.05$, F vs. C).

As expected, a significant increase of plasma corticosterone level was detected in stressed animals on standard diet in comparison to the control animals (Table 1, $p<0.01$, S vs. C), while it was not changed in the liver of fructose-fed stressed animals. The stress treatment also increased intracellular corticosterone level by $45 \%$ in the liver of both groups exposed to stress in comparison to untreated control rats (Table $1, p<0.05$, S vs. C; SF vs. C). The increase of stress hormone is not related to altered GR gene expression since GR mRNA was not changed in any of the examined group (Fig. 1).

Table 1 The effects of high-fructose diet and chronic stress on physiological and biochemical parameters in male Wistar rats

\begin{tabular}{|c|c|c|c|c|c|c|c|}
\hline & \multirow[t]{2}{*}{ Control } & \multirow[t]{2}{*}{ Fructose } & \multirow[t]{2}{*}{ Stress } & \multirow[t]{2}{*}{ Fructose + stress } & \multicolumn{3}{|c|}{ Two-way ANOVA } \\
\hline & & & & & Fructose & Stress & Fructose $\times$ stress \\
\hline Caloric intake (kJ/day/animal) & $182.01 \pm 3.46$ & $261.99 \pm 9.98 * * *$ & $175.68 \pm 4.46$ & $248.68 \pm 9.04 * * *$ & $<0.001$ & NS & NS \\
\hline Body mass (g) & $369 \pm 6.25$ & $330 \pm 14.78$ & $338 \pm 13.11$ & $338 \pm 15.25$ & NS & NS & NS \\
\hline Mass of liver (g) & $15.45 \pm 0.72$ & $16.99 \pm 0.81$ & $14.58 \pm 0.80$ & $16.86 \pm 1.20$ & NS & NS & NS \\
\hline Liver/body ratio $(\times 1000)$ & $41.81 \pm 1.79$ & $52.17 \pm 1.21 *$ & $43.05 \pm 1.35$ & $50.95 \pm 4.72$ & $<0.01$ & NS & NS \\
\hline Plasma CORT (ng/mL) & $168.42 \pm 36.13$ & $196.2 \pm 55.8$ & $523.59 \pm 108 * *$ & $249.67 \pm 52.57$ & NS & $<0.01$ & NS \\
\hline Liver CORT (ng/mg) & $0.33 \pm 0.04$ & $0.38 \pm 0.03$ & $0.48 \pm 0.03^{*}$ & $0.48 \pm 0.04 *$ & NS & $<0.01$ & NS \\
\hline Glucose (mmol/L) & $4.54 \pm 0.13$ & $4.03 \pm 0.14 *$ & $4.18 \pm 0.14$ & $3.92 \pm 0.13 * *$ & $<0.01$ & NS & NS \\
\hline Insulin (mIU/L) & $10.07 \pm 1.85$ & $19.44 \pm 2.45^{*}$ & $10.62 \pm 1.87$ & $20.84 \pm 3.40^{* *}$ & $<0.001$ & NS & NS \\
\hline IPGTT (AUC glucose level) & $960.40 \pm 26.95$ & $1635.00 \pm 206.30 * *$ & $1094.20 \pm 153.90$ & $1010.20 \pm 51.14^{\$}$ & $<0.05$ & NS & $<0.01$ \\
\hline
\end{tabular}

Cumulated caloric intake, body and liver mass, blood glucose, plasma insulin and corticosterone (CORT), quantification of the glycemic excursion during the IPGTT (AUC) and liver corticosterone level were measured after 9 weeks on high-fructose diet and 4 weeks of chronic unpredictable stress in male Wistar rats

All data are presented as means \pm SEM $(n=8-9)$. Comparisons between groups were made by two-way ANOVA followed by post hoc Tukey test. Different symbols denote the values that are significantly different from control group $(* p<0.05, * * p<0.01, * * * p<0.001)$ and fructose-fed group $\left({ }^{\$} p<0.05\right)$

NS non-significant 


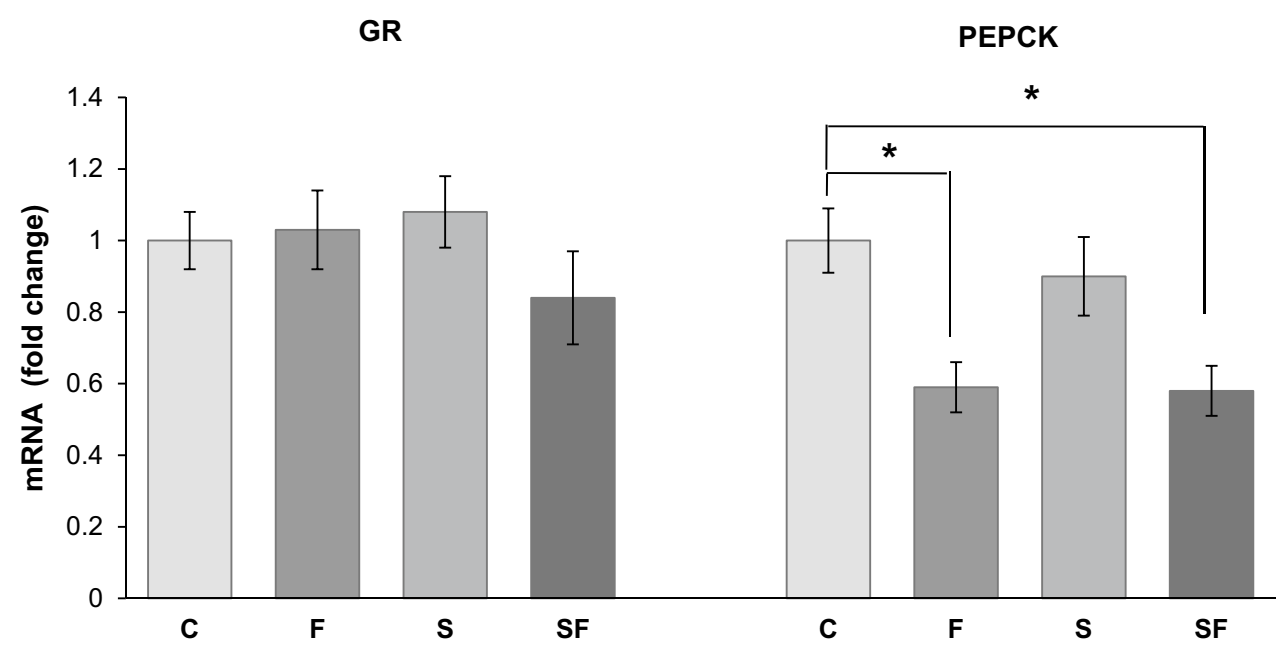

Fig. 1 Effect of high-fructose diet and/or chronic stress on GR and PEPCK mRNA levels in the liver. Relative quantification of GR and PEPCK mRNA levels in the liver was done relative to amount of $\beta$-actin mRNA. Values are means \pm SEM and are presented as fold of control ( $n=6$ rats per group). Comparisons between groups were

\section{High-fructose diet promotes metabolic dysregulation}

Fructose treatment led to a $\sim$ twofold increase of plasma insulin and a decrease of fasting plasma glucose (by $11-13 \%)$ in both fructose and fructose + stress groups (Table $1, p<0.05$, F vs. C; $p<0.01$, SF vs. C). The observed hypoglycemia is in accordance with decreased PEPCK mRNA level in both fructose-fed groups (Fig. 1, $p<0.05$, F vs. C; SF vs. C). The glycemic excursion during the IPGTT was significantly higher in the fructose-fed group compared to untreated controls, as measured by glucose peak level (Fig. 2a, $p<0.05$, F vs. C) and area under the curve (AUC: Table $1, p<0.01, \mathrm{~F}$ vs. C), indicating glucose intolerance. Strikingly, the stress treatment prevented the development of fructose-induced glucose intolerance in fructose + stress rats (Table $1, p<0.05$, SF vs. F). Since glucose intolerance is often linked to disturbed insulin signaling in the liver, we measured a marker of tissue insulin resistance, i.e., the inhibitory phosphorylation of IRS1 at $\mathrm{Ser}^{307}$. High-fructose diet increased the hepatic level of Ser ${ }^{307}$ IRS 1 phosphorylation in both fructose and fructose + stress groups (by 25 and 29\%, respectively) with respect to untreated controls (Fig. $2 \mathrm{~b}, p<0.05$, F vs. C, SF vs. C), pointing to impaired hepatic insulin signaling. Similarly, the hepatic level of phospho $\mathrm{Ser}^{307}$ IRS 1 protein was increased by $40 \%$ in the fructose + stress group compared to stressed animals, which emphasizes the effect of fructose on the inhibitory phosphorylation of IRS 1 (Fig. 2b, $p<0.01$, SF vs. S). Stress alone did not affect the level of phospho $\mathrm{Ser}^{307}$ IRS1 protein. made by two-way ANOVA followed by post hoc Tukey test. Two-way ANOVA demonstrated the significant effect of fructose diet on the PEPCK mRNA $(p<0.001)$. Asterisk indicates significant difference with respect to the control $\left({ }^{*} p<0.05\right)$. Control untreated $(\mathrm{C})$, fructose-fed (F), stressed (S) and fructose-fed stressed (SF) rats
Plasma triglycerides were significantly increased by fructose diet in both groups as compared to the control animals (Table $2, p<0.001$, F vs. C, $p<0.05$, SF vs. C) and decreased in fructose + stress group in comparison to fructose-fed animals $(p<0.05$, SF vs. F). The fatty acid profile of total plasma lipids demonstrated increased palmitic acid (16:0) in both fructose-fed groups compared to untreated control; still, this increase was more prominent in the fructose + stress group (Table $2, p<0.05$, F vs. C; $p<0.01$, SF vs. C). Liver triglycerides were not changed in any of the examined groups, although stressed animals demonstrated slightly decreased hepatic lipids as compared to the control or fructose-fed rats (Table 2). This result was confirmed by histological analysis, which demonstrated that dietary fructose and/or stress treatment did not cause pathological changes or lipid accumulation in the liver (Fig. 3). Fatty acid profile of hepatic lipids revealed significantly increased palmitic, oleic acid (18:1n-9) and monounsaturated fatty acids (MUFA) by fructose diet, irrespective of stress, while PUFA was decreased with fructose diet (Table 2, palmitic acid: $p<0.001$, F vs. C; SF vs. C; oleic acid: $p<0.05$, F vs. C; $p<0.01$, SF vs. C; MUFA, $p<0.05$, F vs. C, $p<0.05$, SF vs. S; PUFA, $p<0.001$, F vs. C, SF vs. C). On the other hand, stearic acid (18:0) was not changed, resulting in increased hepatic $\Delta 9$ desaturase index in both fructosefed groups (Table $2, p<0.05$, F vs. C; $p<0.01$, SF vs. C).

\section{Hepatic inflammation is induced by high-fructose diet}

Fructose intake increased the hepatic level of proinflammatory cytokines TNF $\alpha$ and IL- $1 \beta$ by $45-55 \%$ in the 


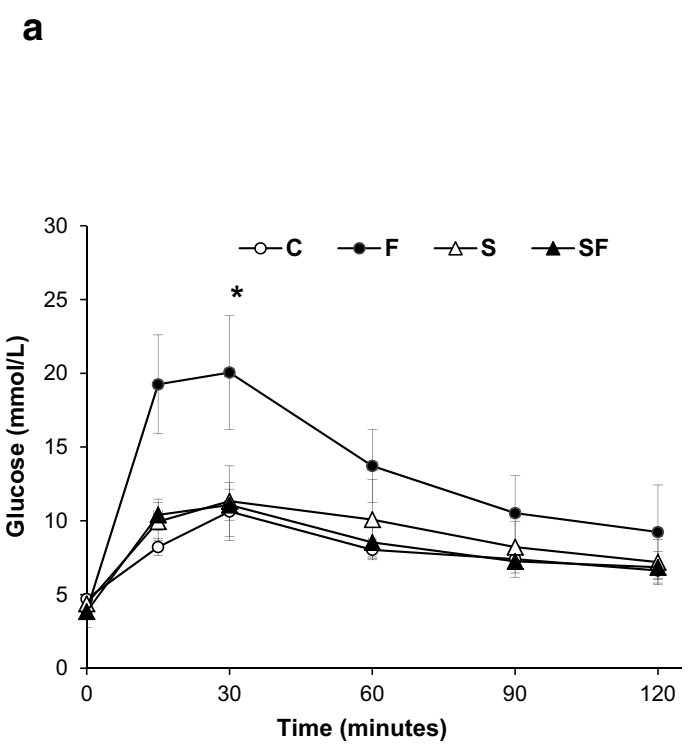

Fig. 2 Effect of high-fructose diet and chronic stress on the indicators of glucose homeostasis [intraperitoneal glucose tolerance test (IPGT) and inhibitory $\mathrm{Ser}^{307}$ phosphorylation of IRS1 (phospho$\mathrm{Ser}^{307}$ IRS1)]. a IPGTT was done in male Wistar rats after overnight fasting. The intraperitoneal injection of glucose $(2 \mathrm{~g} / \mathrm{kg})$ was administered and glucose concentration was determined in the blood drawn from the tail vein before glucose injection and 15, 30, 60, 90, and $120 \mathrm{~min}$ after the injection. Each experimental point represents the mean \pm SEM ( $n=6$ rats per group). b Representative Western blot and relative quantification of the phospho-Ser ${ }^{307}$ IRS1 in the whole cell extract of the liver of control untreated $(\mathrm{C})$, fructose-fed $(\mathrm{F})$, b
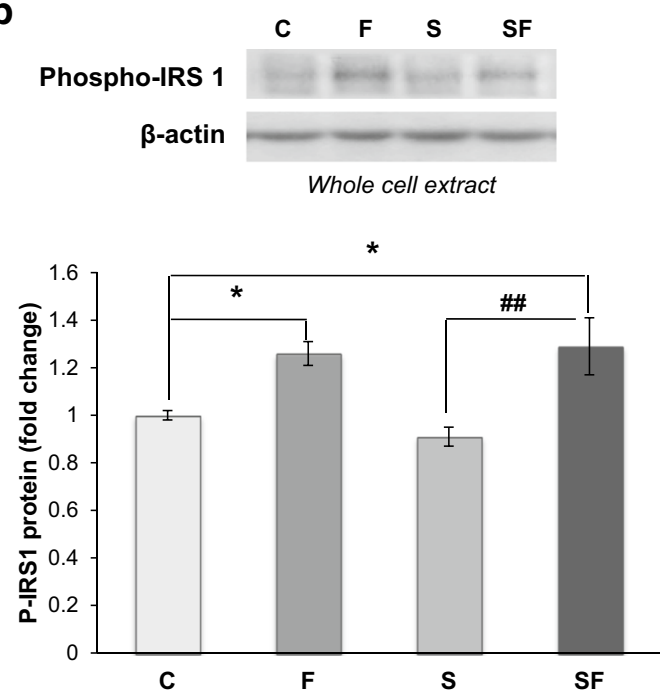

stressed (S) and fructose-fed stressed (SF) rats. Lower part of the blot was probed with antibody against $\beta$-actin that was used as a loading control. Values are means \pm SEM and are presented as fold of control $(n=8-9)$. Comparisons between groups were made by two-way ANOVA followed by post hoc Tukey test. Two-way ANOVA demonstrated the significant effect of fructose diet on the glucose peak level $(p<0.05)$ and on the level of phospho-Ser ${ }^{307}$ IRS1 $(p<0.001)$. Different symbols denote the values that are significantly different from control group $\left({ }^{*} p<0.05\right)$ or stress group $\left.{ }^{\# \#} p<0.01\right)$. Control untreated $(\mathrm{C})$, fructose-fed $(\mathrm{F})$, stressed $(\mathrm{S})$ and fructose-fed stressed (SF) rats

Table 2 Triglyceride (TG) levels and fatty acid alterations in total plasma and hepatic lipids and estimated hepatic $\Delta 9$ desaturase activities in male Wistar rats

\begin{tabular}{|c|c|c|c|c|c|c|c|}
\hline \multirow[t]{2}{*}{ Fatty acid (\%) } & \multirow[t]{2}{*}{ Control } & \multirow[t]{2}{*}{ Fructose } & \multirow[t]{2}{*}{ Stress } & \multirow[t]{2}{*}{ Fructose + stress } & \multicolumn{3}{|c|}{ Two-way ANOVA } \\
\hline & & & & & Fructose & Stress & Fructose $\times$ stress \\
\hline Plasma TG (mmol/L) & $1.09 \pm 0.07$ & $1.94 \pm 0.11^{* * *}$ & $1.0 \pm 0.06$ & $1.55 \pm 0.14^{*} \$$ & $<0.001$ & $<0.05$ & NS \\
\hline Liver TG (mg/g) & $43.76 \pm 5.94$ & $42.11 \pm 4.25$ & $32.26 \pm 4.12$ & $31.54 \pm 1.21$ & NS & $<0.05$ & NS \\
\hline Plasma palmitic acid (16:0) (\%) & $24.58 \pm 0.38$ & $26.13 \pm 0.58 *$ & $23.15 \pm 0.21$ & $26.55 \pm 0.24 * *$ & $<0.001$ & NS & $<0.001$ \\
\hline Hepatic palmitic acid (16:0) (\%) & $19.52 \pm 0.19$ & $21.4 \pm 0.4^{* * *}$ & $18.61 \pm 0,13$ & $21.25 \pm 0.3^{* * *}$ & $<0.001$ & NS & NS \\
\hline Hepatic stearic acid (18:0) (\%) & $17.54 \pm 0.49$ & $16.54 \pm 0.97$ & $18.77 \pm 0.49$ & $15.43 \pm 0.47$ & NS & NS & NS \\
\hline Hepatic oleic acid (18:1n-9) (\%) & $5.85 \pm 0.32$ & $9.29 \pm 1.16^{*}$ & $4.90 \pm 0.21$ & $10.41 \pm 1.14 * *$ & $<0.001$ & NS & NS \\
\hline MUFA (\%) & $9.11 \pm 0.33$ & $14.33 \pm 1.55^{*}$ & $7.61 \pm 0.26$ & $12.84 \pm 1.72^{\#}$ & $<0.001$ & NS & NS \\
\hline PUFA $(\%)$ & $54.78 \pm 0.29$ & $47.72 \pm 1.04 * * *$ & $55.2 \pm 0.17$ & $49.45 \pm 0.97 * * *$ & $<0.001$ & NS & NS \\
\hline$\Delta 9$ desaturase $(18: 1 \mathrm{n}-9 / 18: 0)$ & $0.33 \pm 0.02$ & $0.61 \pm 0.11 *$ & $0.26 \pm 0.01$ & $0.69 \pm 0.09 * *$ & $<0.001$ & NS & NS \\
\hline
\end{tabular}

The data are presented as means \pm SEM $(n=8)$. Fatty acid concentrations are expressed as $\%$ of totally detected fatty acids. Comparisons between groups were made by two-way ANOVA followed by post hoc Tukey test. Different symbols denote the values that are significantly different from control group ( $\left.{ }^{*} p<0.05,{ }^{* *} p<0.01,{ }^{* * *} p<0.001\right)$, fructose-fed group $\left({ }^{\$} p<0.05,{ }^{\$ \$} p<0.001\right)$ and stressed group $\left({ }^{\#} p<0.05\right)$

MUFA monounsaturated fatty acids, $P U F A$ polyunsaturated fatty acids, NS non-significant

fructose-fed group in comparison to untreated control animals (Table $3, p<0.05$, F vs. C, for both TNF $\alpha$ and IL- $1 \beta$ ). Similarly, TNF $\alpha$ and IL-1 $\beta$ were increased by $54-60 \%$ in the fructose + stress group as compared to the stress group
(Table $3, p<0.05$, SF vs. S, for both cytokines). Stress generally tended to decrease by $\sim 20 \%$ the hepatic protein levels of TNF $\alpha$ and IL- $1 \beta$ in the fructose + stress group compared to fructose-fed animals, although this trend did not reach 

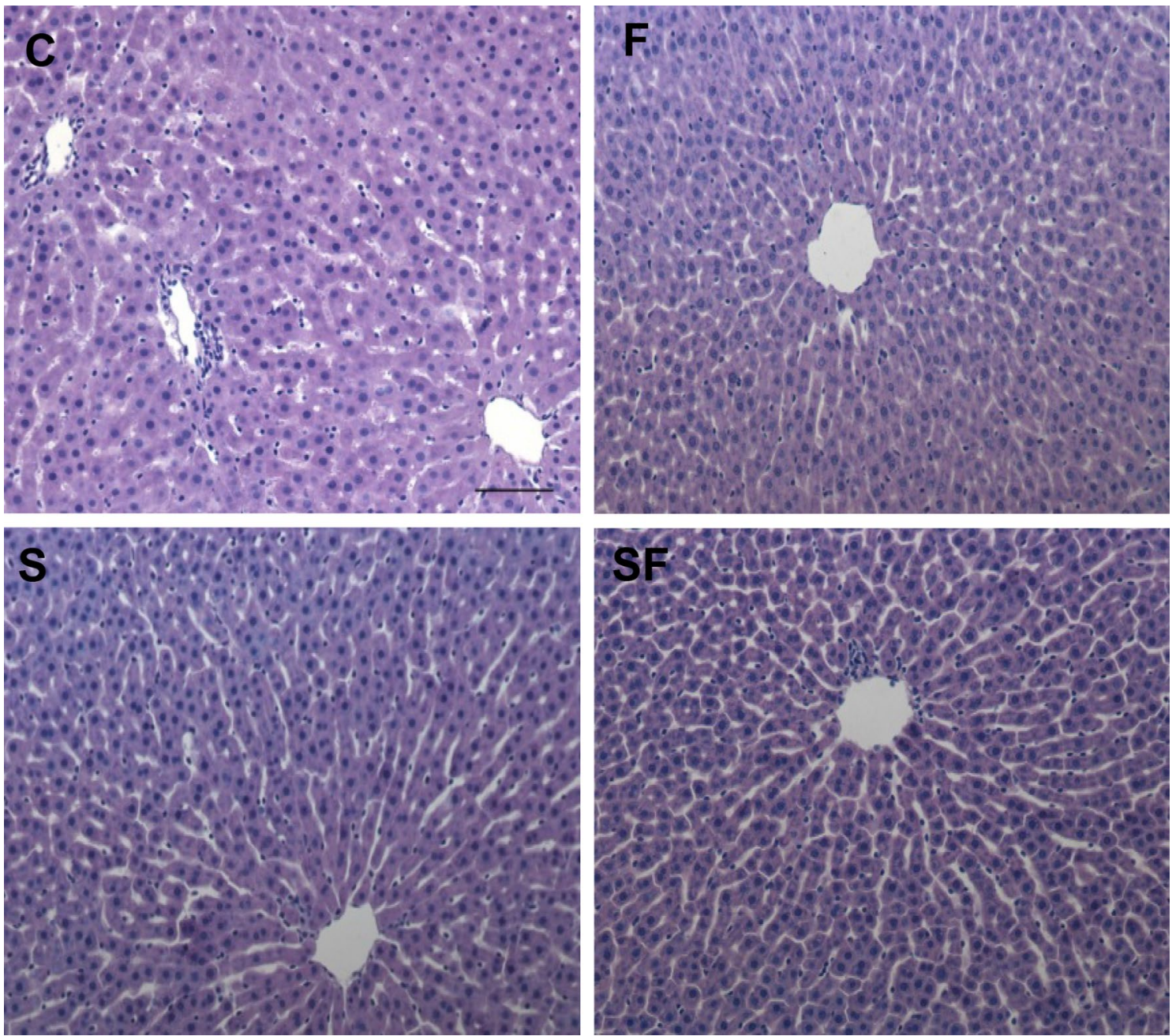

Fig. 3 Histological analysis of the liver after high-fructose diet and chronic stress. Representative micrographs of hematoxylin-eosin-stained sections of hepatic tissue of control (C), fructose (F), stress (S) and stress + fructose (SF) groups of animals. Scale bar: $100 \mu \mathrm{m}$

Table 3 Cytokine concentrations in the liver after high-fructose diet and chronic stress

\begin{tabular}{|c|c|c|c|c|c|c|c|}
\hline \multirow{2}{*}{ 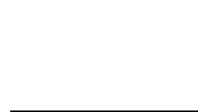 } & \multirow{2}{*}{ Control } & \multirow[t]{2}{*}{ Fructose } & \multirow{2}{*}{ Stress } & \multirow{2}{*}{ Fructose + stress } & \multicolumn{3}{|c|}{ Two-way ANOVA } \\
\hline & & & & & Fructose & Stress & Fructose $\times$ stress \\
\hline $\mathrm{TNF} \alpha(\mathrm{pg} / \mathrm{mg})$ & $33.37 \pm 3.38$ & $51.52 \pm 1.88^{*}$ & $26.82 \pm 2.20$ & $40.96 \pm 5.11^{\#}$ & $<0.001$ & $<0.05$ & NS \\
\hline IL-1 $\beta(\mathrm{pg} / \mathrm{mg})$ & $85.53 \pm 8.83$ & $124.13 \pm 6.72 *$ & $66.96 \pm 5.35$ & $107.54 \pm 12.61^{\#}$ & $<0.001$ & 0.06 & NS \\
\hline IL-6 (pg/mg) & $698.36 \pm 50.37$ & $888.18 \pm 56.54$ & $491.72 \pm 32.03$ & $1069.6 \pm 120.6^{*}$ & $<0.001$ & NS & $<0.05$ \\
\hline IL-4 (pg/mg) & $77.03 \pm 8.18$ & $94.91 \pm 7.34$ & $82.87 \pm 5.19$ & $99.68 \pm 11.6$ & NS & NS & NS \\
\hline IL-10 (pg/mg) & $254.01 \pm 20.68$ & $247.55 \pm 57.57$ & $149.93 \pm 14.5$ & $311.64 \pm 72.28$ & NS & NS & NS \\
\hline
\end{tabular}

The levels of proinflammatory and anti-inflammatory cytokines in the hepatic whole cell extracts were determined by ELISA test

The data are presented as means \pm SEM $(n=6-8)$. Comparisons between groups were made by two-way ANOVA followed by post hoc Tukey test. Different symbols denote the values that are significantly different from control group $\left({ }^{*} p<0.05\right)$ or stress group $\left({ }^{\#} p<0.05\right.$, $\left.{ }^{\# \#} p<0.001\right)$

NS non-significant

statistical significance (Table 3). As a result, TNF $\alpha$ and IL-1 $\beta$ protein levels, which were increased in the fructoseonly group compared to controls, were not significantly different in the fructose + stress group as compared to controls (Table 3). A different pattern was observed for hepatic IL-6 protein that was increased only in fructose + stress 
group in comparison to untreated controls and stress group (Table 3, $p<0.05$, SF vs. C; $p<0.001$, SF vs. S). Concentrations of anti-inflammatory cytokines IL-4 and IL-10 were not significantly affected by any treatment (Table 3 ).

Proinflammatory protein NFKB is a key mediator of metabolic inflammation in response to cytokine activation. Upon stimulation, the inhibitory protein $\mathrm{I} \kappa \mathrm{B}$ is phosphorylated and dissociates from $\mathrm{NF \kappa B}$, allowing its nuclear translocation. While the treatments had no effect on NFKB levels in the cytoplasmic fraction (Fig. 4a), fructose feeding increased the nuclear levels of NFKB by $30 \%$ in the liver of fructosefed unstressed rats in comparison to untreated control animals (Fig. 4a, $p<0.05$, F vs. C). Interestingly, this response to fructose was moderately blunted by stress $(-23 \%)$ after combined treatment, as compared to fructose-fed animals, although this change was not statistically significant. Consistent with these data, phosphorylated $\mathrm{I} \kappa \mathrm{B}$ cytoplasmic level was increased by $\sim 20 \%$ upon high-fructose diet as compared to controls (Fig. 4b, $p<0.01$, F vs. C; $p<0.05$, $\mathrm{SF}$ vs. C), while total $\mathrm{I} \kappa \mathrm{B}$ was not changed. This resulted in the increased phospho-I $\mathrm{KB} /$ total $\mathrm{I} \kappa \mathrm{B}$ ratio only in the fructose-fed group (Fig. 4b, $p<0.01$, F vs. C), an effect that was partially reduced by stress in the fructose + stress group (Fig. 4b, $p<0.05$, SF vs. F).

Since both high-fructose diet and stress can modulate gut permeability and release of bacterial toxins into circulation,

\section{a}

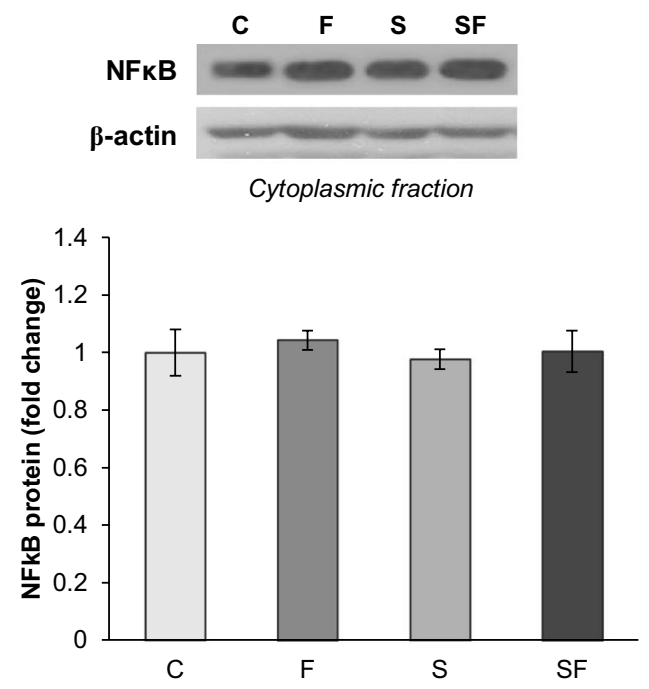

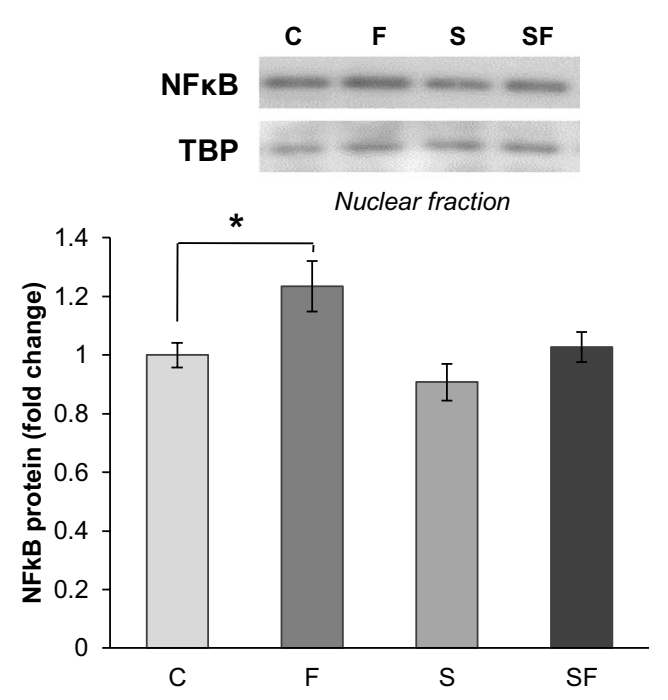

b

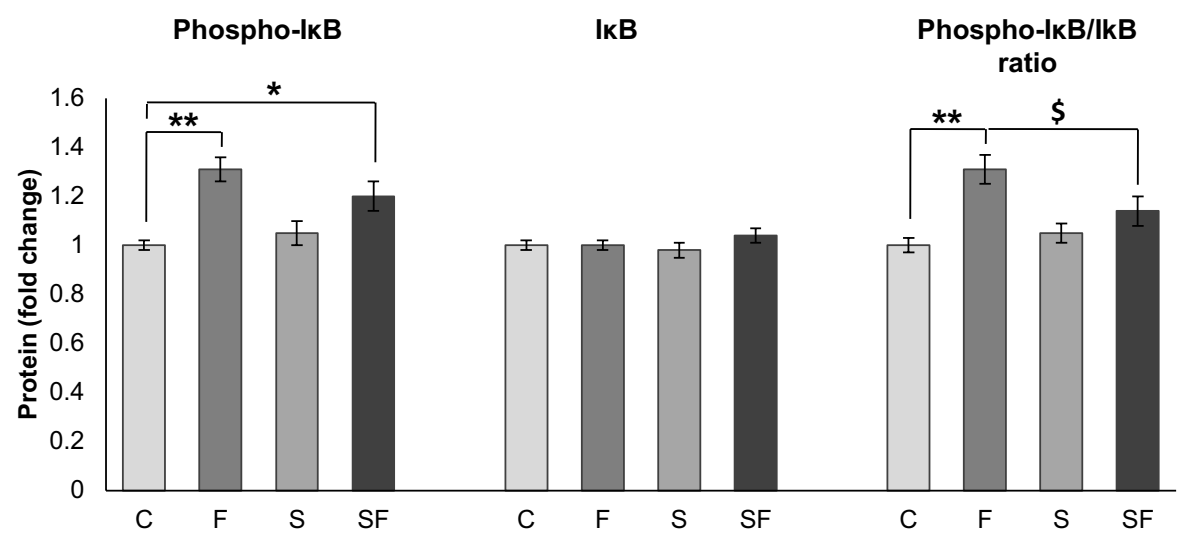

Fig. 4 The subcellular distribution of NFKB and the levels of total

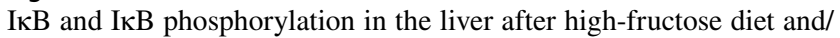
or chronic stress. Representative Western blots and relative quantification of NFKB protein level in cytoplasmic and nuclear fraction (a) and phospho-I $\kappa \mathrm{B}$ and total $\mathrm{I} \kappa \mathrm{B}$ in the cytoplasmic fraction (b) of the liver of control untreated (C), fructose-fed (F), stressed (S) and fructose-fed stressed (SF) rats. Lower parts of the blots were probed with antibodies against $\beta$-actin and TATA-binding protein (TBP) that were used as loading controls for cytoplasmic and nuclear fraction, respectively. Values are means \pm SEM and are presented as fold of control $(n=8-9)$. Comparisons between groups were made by twoway ANOVA followed by post hoc Tukey test. Two-way ANOVA indicated the main effect of fructose diet on NFKB nuclear level $(p<0.01)$, on the IкB phosphorylation $(p<0.01)$, as well as significant interaction of fructose diet and stress on the IкB phosphorylation $(p<0.05)$. Different symbols denote the values that are significantly different from control group $(* p<0.05, * * p<0.01)$ or fructose-fed group $\left({ }^{\$} p<0.05\right)$ 
we examined the expression of liver inflammatory marker activated by bacterial toxins such as TLR4 and NLRP3. The results demonstrated increased TRL4 mRNA in both stressed groups (Fig. 5a, $p<0.01$, S vs. C; SF vs. C), clearly pointing out the effects of stress on this receptor. The increment of TRL 4 mRNA by $70 \%$ is also evident when fructose + stress group is compared to fructose-fed animals (Fig. 5a, $p<0.05$, SF vs. F). On the other hand, NLRP3 protein was not changed in any of the examined groups (Fig. 5b), which suggests that this mechanism is not involved in the fructose-induced hepatic inflammation.

Other important components in the regulation of both metabolic inflammation and insulin resistance in the liver are JNK1/2 and ERK kinases. The activity of JNK1 (as reflected by the ratio of phosphorylated $\mathrm{p} 46$ isoform at $\mathrm{Thr}^{183} / \mathrm{Tyr}^{185}$ and total JNK1) was increased by fructose feeding by $29 \%$ (Fig. $6 \mathrm{a}, p<0.05$, F vs. C). On the other hand, the level of ERK activity (as reflected by the ratio of phosphorylated ERK at $\mathrm{Thr}^{202} / \mathrm{Tyr}^{204}$ and total ERK protein) was not altered by the treatments (Fig. 6b). Thus, fructose feeding promoted hepatic inflammation, an effect that was partially attenuated by stress.

\section{Effects of high-fructose diet and/or stress on the levels of energy sensors in the liver}

To assess whether fructose feeding alters energy-sensing pathways in the liver, we measured activation indexes of

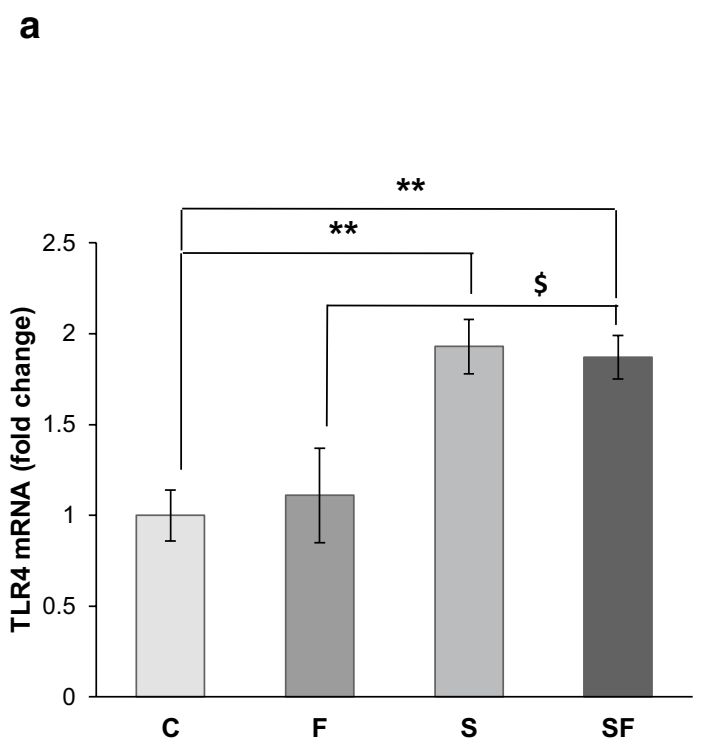

Fig. 5 The levels of TLR4 mRNA and NLRP3 protein in the liver after high-fructose diet and chronic stress. Relative quantification of TLR4 mRNA (a) and NLRP3 protein (b) in the liver of control untreated (C), fructose-fed (F), stressed (S) and fructose-fed stressed (SF) rats was done relative to level of $\beta$-actin mRNA and protein, respectively. Values are means \pm SEM and are presented as fold of hepatic AMPK, SIRT1 and PGC-1 $\alpha$ signaling. In parallel with increased hepatic inflammation, fructose decreased the ratio of cytoplasmic phospho-Tyr ${ }^{172}$ AMPK/total AMPK by 23 and $29 \%$ in fructose and fructose + stress groups, respectively, compared to controls, suggesting a decrease in AMPK hepatic activity (Fig. 7a, $p<0.01$, F vs. C; SF vs. C). Of note, the decreased phospho-AMPK/ total AMPK ratios in these groups were due to a significant increase of total AMPK protein (+40 and $+48 \%$ ) (Fig. 7a, $p<0.01$, F vs. C; SF vs. C, medium panel) rather than a decrease in phosphorylation (Fig. 7a, left panel). Stress treatment alone tended to decrease phospho-AMPK/total AMPK ratio, but this effect did not reach statistical significance (Fig. 7a, $p=0.063$, S vs. C). The increased total AMPK protein was not the result of altered gene expression since AMPK mRNA was not changed after applied treatments (Fig. 7b). In addition, SIRT1 protein expression was increased in the liver of unstressed fructose-fed animals as compared to untreated control group (Fig. 7c, $p<0.05$, F vs. C). Although the same trend was observed in the fructose + stress group, the fructose effect was attenuated by stress and did not reach statistical difference compared to both control and stress groups. Furthermore, nuclear levels of PGC- $1 \alpha$ were not affected by either dietary fructose and/or stress (Fig. 7d).

b
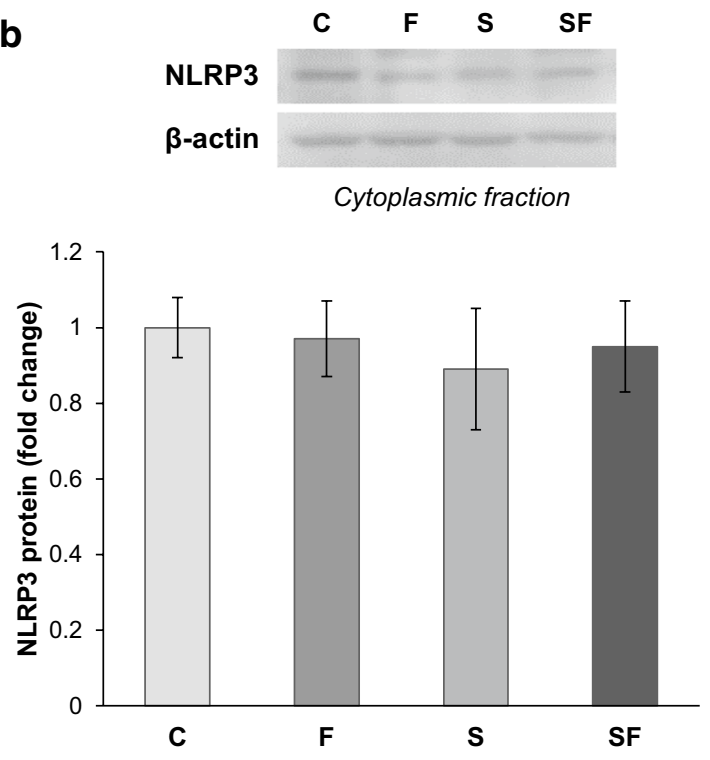

control $(n=8-9)$. Comparisons between groups were made by twoway ANOVA followed by post hoc Tukey test. Two-way ANOVA indicated the main effect of stress on the TLR4 mRNA $(p<0.001)$. Different symbols denote the values that are significantly different from control group $(* * p<0.01)$ or fructose-fed group $\left({ }^{*} p<0.05\right)$ 


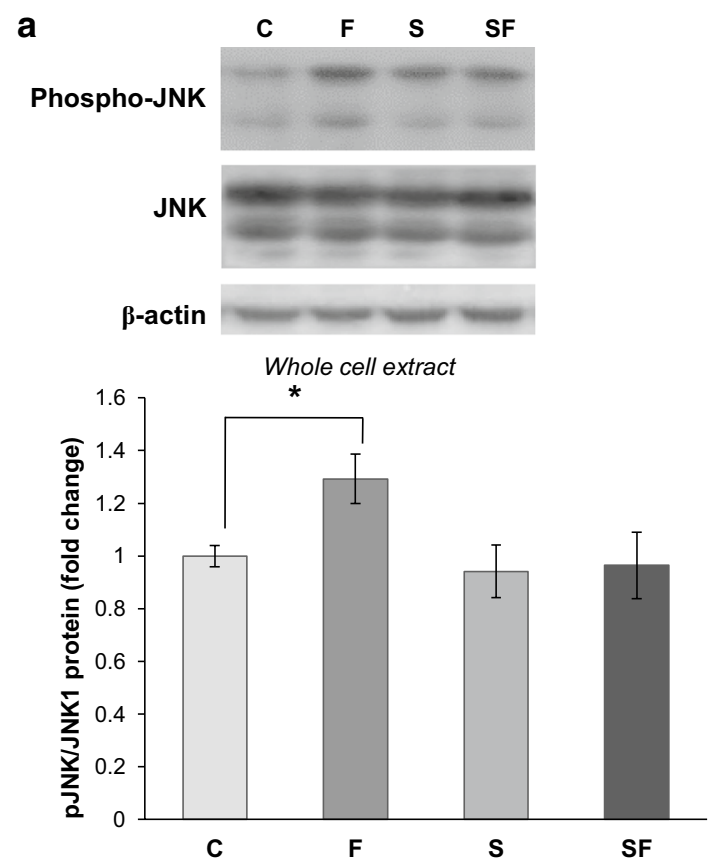

Fig. 6 The levels of JNK and ERK phosphorylation in the liver after high-fructose diet and chronic stress. Representative Western blots and relative quantification of phospho-JNK1 (p46 isoform)/ total JNK1 (a) and phospho-ERK/total ERK (b) ratio in the liver of control untreated $(\mathrm{C})$, fructose-fed $(\mathrm{F})$, stressed $(\mathrm{S})$ and fructose-fed stressed (SF) rats. Lower parts of the blots were probed with antibodies against $\beta$-actin as loading control for whole cell extract. Values

\section{Discussion}

In this study, we demonstrated that high-fructose diet triggered hepatic inflammation, characterized by the activation of NFKB and JNK signaling pathways and increased levels of proinflammatory cytokines TNF $\alpha$ and IL-1 $\beta$. Fructose overload also resulted in hypertriglyceridemia, glucose intolerance and impaired hepatic insulin signaling, but without ectopic lipid accumulation in the liver. These metabolic perturbations were accompanied by decreased hepatic AMPK activity. On the other hand, when high-fructose diet was applied together with chronic unpredictable stress, hepatic inflammation was partially prevented and glucose tolerance was preserved, most likely due to anti-inflammatory effects of glucocorticoids in the liver.

Many studies have linked fructose overconsumption to the development of obesity and metabolic disorders [35]. In the present study, both fructose-fed groups had decreased solid food intake, but increased total energy intake compared to the rats on standard chow diet. Fructose diet did not increase liver or body weight in any of examined groups. Namely, other studies showed that a longer exposure to high-fructose diet (above 20 weeks) is needed to induce weight gain [36]. Still, the liver-to-body weight ratio was b
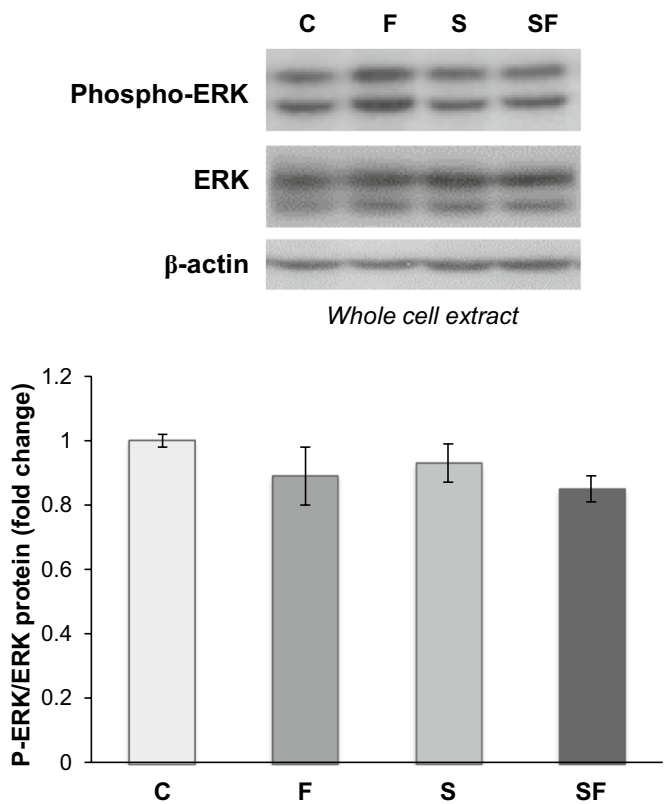

are means \pm SEM and are presented as fold of control $(n=8-9)$. Comparisons between groups were made by two-way ANOVA followed by post hoc Tukey test. Two-way ANOVA showed that high-fructose diet is the main factor affecting JNK1 activity (ratio of phosphoJNK1 and total JNK1) $(p<0.01)$. Asterisk indicates significant difference with respect to the control $(* p<0.05)$

increased in fructose-fed unstressed animals, which was not related to increased hepatic triglycerides. Moreover, histological analysis did not show ectopic accumulation of hepatic lipids or signs of hepatic steatosis in any of examined groups. Although fructose is referred to as lipogenic sugar, essential for the development of hepatic steatosis is higher fructose concentration [37] or prolonged treatment (more than 10 weeks) [38]. Still, the results from the present study confirmed hypertriglyceridemia and altered hepatic fatty acids composition as metabolic hallmarks of fructose-enriched diet. Namely, hepatic fatty acid profile was characterized by a higher proportion of MUFA, lower proportion of PUFA and increased oleic/stearic acid ratio ( $\Delta 9$ desaturase index), regardless of stress. These results are in accordance with other animal studies using high-fructose diet [39-41]. In addition, it was previously demonstrated that fructose-induced increase of MUFA and decrease of PUFA in the liver were not accompanied by lipid accumulation and hepatic steatosis $[39,40]$, but rather with increased secretion of triglycerides, as observed in the present study.

Chronic unpredictable stress increased plasma corticosterone in stressed rats, which points to the activation of HPA axis and normal physiological response to chronic stress [42]. Interestingly, when stress was combined with dietary 
a

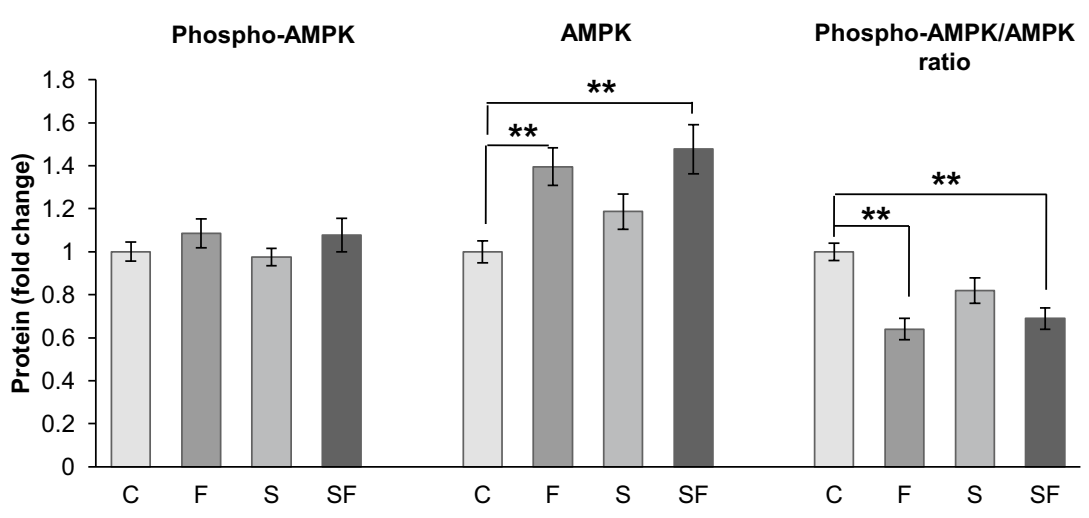

b

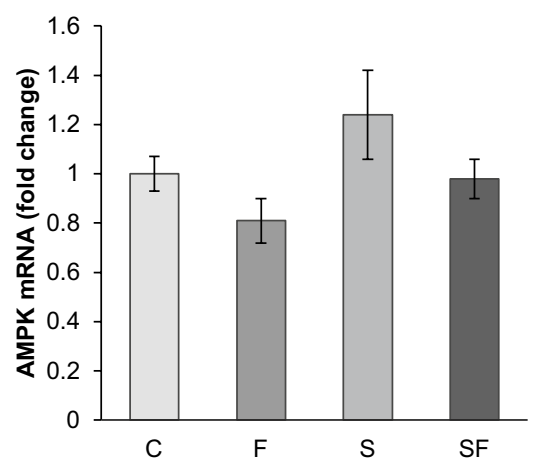

c
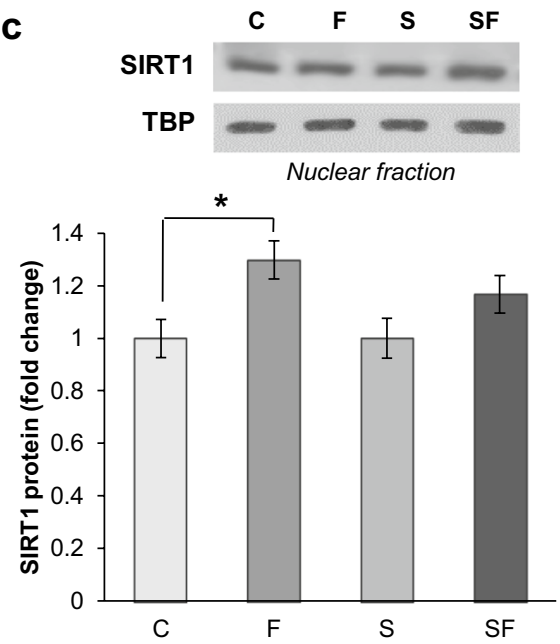

d

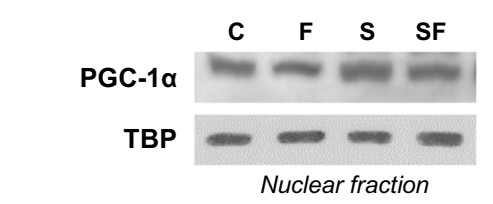

Fig. 7 The level of total AMPK, AMPK phosphorylation, SIRT1 and PGC- $1 \alpha$ in the liver after high-fructose diet and chronic stress. Representative Western blots and relative quantification of phosphoAMPK, total AMPK and phospho-AMPK/AMPK ratio in the cytoplasmic fraction (a), AMPK mRNA (b), SIRT1 (c) and PGC-1 $\alpha$ protein levels in the nucleus (d) of the liver of control untreated (C), fructose-fed (F), stressed (S) and fructose-fed stressed (SF) rats. Relative quantification of proteins (a, c, d) and AMPK mRNA (b) levels were done relative to amount of $\beta$-actin protein and mRNA, respectively. Values are means \pm SEM and are presented as fold of control $(n=8-9)$. Comparisons between groups were made by twoway ANOVA followed by post hoc Tukey test. Two-way ANOVA revealed the effect of fructose diet on total AMPK $(p<0.001)$, on phospho-AMPK/total AMPK ratio $(p<0.01)$ and significant interaction between fructose diet and stress on phospho-AMPK/total AMPK ratio $(p<0.05)$, as well as the main effect of fructose diet on SIRT1 protein level $(p<0.01)$. Asterisks indicate significant difference with respect to the control $(* p<0.05, * * p<0.01)$ fructose, the stress-induced rise of plasma corticosterone was absent, most likely due to reduced central reactivity of HPA axis [43]. On the other hand, hepatic corticosterone was increased in both stress and fructose + stress groups, possibly as a result of enhanced glucocorticoid prereceptor metabolism induced by high-fructose diet [27]. This state did not affect GR gene expression, as revealed in this and our previous study, but rather led to activation and nuclear accumulation of GR [44]. In addition, chronic stress per se did not alter glucose homeostasis, which is in line with previous reports that chronic mild stress has relatively modest effects on glucose homeostasis that occurs primarily at the beginning of stress exposure [45]. On the other hand, fructose-fed unstressed animals displayed altered glucose homeostasis, as characterized by hypoglycemia, hyperinsulinemia and impaired glucose tolerance, as revealed by IPGTT. Other studies also demonstrated that high-fructose diet induces hyperinsulinemia, disturbs both glucose and insulin tolerance [46], evokes insulin resistance and delays glucose disappearance rate [47]. The observed hypoglycemia in the fructose-fed animals is most likely the result of decreased expression of key gluconeogenic enzyme PEPCK, which is in accordance with previous studies on fructose-fed rats [27, 36]. Interestingly, in the fructose + stress group, the stress treatment prevented the fructose-induced glucose intolerance, which is supported by previous research indicating that chronic variable stress (CVS) improves glucose tolerance in sucrose-fed rats [48]. Indeed, in that study, CVS induced beneficial effects not through changes in fasting glucose, insulin or corticosterone, but rather through a 
faster stress-related glucose clearance [48]. Therefore, in our animal model, the high-fructose diet induced glucose intolerance and prediabetes, an effect that was prevented by the stress treatment.

Fructose diet increased hepatic levels of proinflammatory cytokines TNF $\alpha$ and IL-1 $\beta$, while pro-inflammatory IL-6 and anti-inflammatory cytokines IL-4 and IL-10 remained unchanged, consistent with hepatic inflammation $[49,50]$. The increased hepatic cytokine levels could be mediated by proinflammatory NFKB and JNK signaling pathways in the liver [51]. Indeed, consistent with previous reports [52], fructose consumption increased both the hepatic NFKB signaling, as indicated by I $\mathrm{KB} \alpha$ phosphorylation and $\mathrm{NF \kappa B}$ nuclear translocation, and JNK signaling, as revealed by the increase in the phospho-JNK1 to total JNK1 ratio. Consistent with the fact that NFKB and JNK signaling have been implicated in insulin resistance, fructose feeding increased the inhibitory phosphorylation of IRS 1 on the $\mathrm{Ser}^{307}$, which represents an early hallmark of tissue insulin resistance [51]. On the other hand, hepatic ERK signaling pathway, which also regulates insulin sensitivity through inhibitory phosphorylation of IRS1 on $\operatorname{Ser}^{612}$ [6], was not changed in these animals. Therefore, high-fructose diet induced the vicious cycle comprised of hepatic inflammation, decreased hepatic insulin sensitivity and glucose intolerance [53].

It is not fully understood how excess nutrients are sensed within the cells and how they promote the inflammatory program in the context of high-fructose diet. Several studies have revealed a close link between metabolic inflammation and reduced AMPK activity, e.g., in adipose tissue and heart $[11,54]$, and few studies have investigated the relationship between fructose-induced inflammation and AMPK signaling pathway. In our study, high-fructose diet diminished hepatic AMPK activity, represented as decreased phospho-AMPK/AMPK ratio [55]. In agreement with the results obtained by Chen et al. [56], high-fructose diet increased total AMPK level without significantly affecting phospho-AMPK. Several mechanisms could account for the observed effects of fructose diet on the AMPK activity. Previous study demonstrated that elevated insulin can significantly increase total AMPK $\alpha$ protein level without affecting AMPK phosphorylation level [57], which is in accordance with the results obtained in the present study. In addition, according to study by Beauloye et al. [58], inhibitory effect of insulin on AMPK protein is reflected in its decreased activity. However, in our study, the observed phenomenon was not related to the altered expression of AMPK gene, but possibly to AMPK phosphorylation at $\mathrm{Ser}^{485}$ driven by insulin-induced Akt, which reduces $\mathrm{Thr}^{172}$ phosphorylation and inhibits AMPK activation [58]. Furthermore, high-fructose diet, via the increase in methylglyoxal production, could provoke carbonyl stress on AMP binding sites in AMPK, thus irreversibly blocking the phosphorylation of AMPK on
$\mathrm{Thr}^{172}$ and its activation [59]. It is conceivable that fructoseinduced hepatic inflammation through the stimulation of the NFkB signaling pathway is facilitated by decreased AMPK activity, as observed in the fructose-fed group [16]. This hypothesis is supported by prior findings that consumption of $30 \%$ fructose solution leads concomitantly to increased pro-inflammatory cytokines and decreased phospho-AMPK/ AMPK ratio in the rat liver [56] and that fructose-induced inflammation and NFKB activation in the diabetic murine heart is causally related to reduced AMPK activity [12]. The suggested role of AMPK as an important energy sensor linking fructose metabolism to the regulation of inflammatory signaling is further supported by recent findings of Cao et al. [60], showing that fructose amplifies inflammatory potential in human monocytic cells via a reduction of AMPK activity. However, high fructose concentrations in the liquid form can affect gut permeability, leading to the leakage of bacteria and their endotoxins into the circulation [61]. Therefore, metabolic effects of fructose on hepatic inflammation may not be direct but then conducted through the toxic effects of bacterial products on the liver cells, especially through activation of TLR4 [62] and NLRP3 inflammasome [63]. However, in the present study, both TRL4 mRNA and NLRP3 protein were unchanged in the fructose-fed group, suggesting that this mechanism was not involved in the observed fructose-induced hepatic inflammation. Interestingly, the results clearly showed the effect of stress on TRL4 mRNA, which was increased in all stressed rats independently of fructose diet. This could be a consequence of increased saturated palmitic and oleic fatty acids in the plasma lipids of fructose + stress group, observed in this and our previous study [64], which can act as endogenous TLR4 ligands in hepatic cells [65]. However, this was not accompanied with increased NLRP3 protein or activated NFKB signaling pathway. Consequently, stress treatment alone did not change any of the monitored cytokines and did not alter the expression of proinflammatory kinases as compared to the control group. Namely, chronic restraint stress could promote immune suppression through activation of TLR4 and subsequent modulation of phosphoinositide 3-kinase (PI3K)/ Akt signaling [66]. Therefore, after combined treatment stress generally tended to decrease the expression of proinflammatory cytokines, although a significant protective effect was observed only for TNF $\alpha$ and IL- $1 \beta$ proteins in the proinflammatory context of fructose feeding in the fructose + stress group. On the contrary, the combined treatment increased only IL-6 levels while did not affect anti-inflammatory cytokines (IL-4, IL-10). This is overall in agreement with previous finding that chronic psychological stress mitigates the effects of high-fructose-high-fat diet on hepatic inflammation [22], by promoting an adaptive anti-inflammatory response. This effect of stress most likely results from the observed increase in hepatic corticosterone that generally 
inhibits inflammation. However, consistent with our results, corticosterone can stimulate the synthesis and production of IL-6 through prolonged activation of signal transducer and activator of transcription 3 (STAT3) [67]. The increased IL-6 levels could account for the increased inhibitory IRS1 $\mathrm{Ser}^{307}$ phosphorylation in the group subjected to combined treatment, in the absence of JNK1 activation and probably through the Janus kinase (JAK)/STAT pathway [68]. Nevertheless, in spite of signs of hepatic insulin resistance, animals in the fructose + stress group demonstrated preserved glucose tolerance, which implies dissociation of these two events and involvement of other insulin-sensitive tissues, like muscle or adipose tissue, in the regulation of glucose metabolism [69].

Intriguingly, although AMPK activation is reduced in both fructose groups regardless of stress, it is not followed by increased inflammation and activation of NFKB pathway after combined treatment. This is most likely an outcome of increased level of corticosterone and its anti-inflammatory activity in the liver of these animals, which through decreased phospho-ІкB/IкB ratio could directly inhibit the NFkB signaling pathway [70].

There are multiple mechanisms by which AMPK may alter NFאB activity, including AMPK-downstream regulators such as SIRT1, PGC-1 $\alpha$ and forkhead box protein O1 (FoxO1) [16]. However, SIRT1 and PGC-1 $\alpha$ were not decreased with high-fructose diet in our study, and hence could not be considered as mediators of fructose-induced inflammation. Another possible mechanism for increased inflammation may be a decreased phosphorylation of FoxO1 and a consequent stimulation of inflammation [71]. This hypothesis is supported by previous reports that highfructose diet leads to increased nuclear FoxO1 in the rat and hamster liver [72], while augmented FoxO1 expression potentiates pro-inflammatory cytokine production in the liver of diabetic mice [71].

In summary, this study suggests that high-fructose diet resulted in decreased AMPK activity, induced hepatic inflammation, impaired glucose tolerance and hepatic insulin signaling, without concomitant lipid accumulation or hepatic steatosis. Chronic stress alone had no effect on AMPK activity, hepatic inflammation and insulin sensitivity. Chronic stress combined with a high-fructose diet did not prevent fructose-induced suppression of AMPK activity but could restore glucose tolerance and partially prevent development of hepatic inflammation. Future studies are warranted to determine the exact role of AMPK in fructoseinduced hepatic inflammation.

Acknowledgements This work was supported by the Ministry of Education, Science and Technological Development of the Republic of Serbia (Grant III41009) and SCOPES JRP (Grant no. IZ73ZO_152331). The authors gratefully appreciate Dr. Đurđica Ignjatović for providing ERK and phospho-ERK antibodies, Dr. Desa Milanović for providing
phospho-AMPK antibody and Dr. Ivana Stojanović for providing NLRP3 antibody.

\section{Compliance with ethical standards}

Conflict of interest On behalf of all authors, the corresponding author states that there is no conflict of interest.

\section{References}

1. Dekker MJ, Su Q, Baker C, Rutledge AC, Adeli K (2010) Fructose: a highly lipogenic nutrient implicated in insulin resistance, hepatic steatosis, and the metabolic syndrome. Am J Physiol Endocrinol Metab 299:E685-E694. https://doi.org/10.1152/ajpen do.00283.2010

2. Yau YH, Potenza MN (2013) Stress and eating behaviors. Minerva Endocrinol 38:255-267

3. Kuo LE, Kitlinska JB, Tilan JU, Li L, Baker SB, Johnson MD, Lee EW, Burnett MS, Fricke ST, Kvetnansky R, Herzog H, Zukowska Z (2007) Neuropeptide Y acts directly in the periphery on fat tissue and mediates stress-induced obesity and metabolic syndrome. Nat Med 13:803-811. https://doi.org/10.1038/nm1611

4. Dandona P, Aljada A, Bandyopadhyay A (2004) Inflammation: the link between insulin resistance, obesity and diabetes. Trends Immunol 25:4-7

5. Le Marchand-Brustel Y, Gual P, Gremeaux T, Gonzalez T, Barres R, Tanti JF (2003) Fatty acid-induced insulin resistance: role of insulin receptor substrate 1 serine phosphorylation in the retroregulation of insulin signalling. Biochem Soc Trans 31:1152-1156. https://doi.org/10.1042/BST0311152

6. Lee YH, Giraud J, Davis RJ, White MF (2003) c-Jun N-terminal kinase (JNK) mediates feedback inhibition of the insulin signaling cascade. J Biol Chem 278:2896-2902. https://doi.org/10.1074/jbc. M208359200

7. Jiao P, Feng B, Li Y, He Q, Xu H (2013) Hepatic ERK activity plays a role in energy metabolism. Mol Cell Endocrinol 375:157166. https://doi.org/10.1016/j.mce.2013.05.021

8. Carling D, Thornton C, Woods A, Sanders MJ (2012) AMPactivated protein kinase: new regulation, new roles? Biochem J 445:11-27. https://doi.org/10.1042/BJ20120546

9. Ruderman NB, Carling D, Prentki M, Cacicedo JM (2013) AMPK, insulin resistance, and the metabolic syndrome. J Clin Invest 123:2764-2772. https://doi.org/10.1172/JCI67227

10. Lyons CL, Kennedy EB, Roche HM (2016) Metabolic inflammation-differential modulation by dietary constituents. Nutrients. https://doi.org/10.3390/nu8050247

11. Ko HJ, Zhang Z, Jung DY, Jun JY, Ma Z, Jones KE, Chan SY, Kim JK (2009) Nutrient stress activates inflammation and reduces glucose metabolism by suppressing AMP-activated protein kinase in the heart. Diabetes 58:2536-2546. https://doi.org/10.2337/ db08-1361

12. Zhao C, Zhang Y, Liu H, Li P, Zhang H, Cheng G (2017) Fortunellin protects against high fructose-induced diabetic heart injury in mice by suppressing inflammation and oxidative stress via AMPK/Nrf-2 pathway regulation. Biochem Biophys Res Commun 490:552-559. https://doi.org/10.1016/j.bbrc.2017.06.076

13. Mancini SJ, White AD, Bijland S, Rutherford C, Graham D, Richter EA, Viollet B, Touyz RM, Palmer TM, Salt IP (2017) Activation of AMP-activated protein kinase rapidly suppresses multiple pro-inflammatory pathways in adipocytes including IL-1 receptor-associated kinase-4 phosphorylation. Mol Cell Endocrinol 440:44-56. https://doi.org/10.1016/j.mce.2016.11.010 
14. Bess E, Fisslthaler B, Fromel T, Fleming I (2011) Nitric oxideinduced activation of the AMP-activated protein kinase alpha2 subunit attenuates IkappaB kinase activity and inflammatory responses in endothelial cells. PLoS One 6:e20848. https://doi. org/10.1371/journal.pone.0020848

15. Ghosh S, May MJ, Kopp EB (1998) NF-kappa B and Rel proteins: evolutionarily conserved mediators of immune responses. Annu Rev Immunol 16:225-260. https://doi.org/10.1146/annur ev.immunol.16.1.225

16. Salminen A, Hyttinen JM, Kaarniranta K (2011) AMP-activated protein kinase inhibits NF-kappaB signaling and inflammation: impact on healthspan and lifespan. J Mol Med 89:667-676. https://doi.org/10.1007/s00109-011-0748-0

17. Yang XD, Tajkhorshid E, Chen LF (2010) Functional interplay between acetylation and methylation of the RelA subunit of NFkappaB. Mol Cell Biol 30:2170-2180. https://doi.org/10.1128/ MCB.01343-09

18. Kim HJ, Park KG, Yoo EK, Kim YH, Kim YN, Kim HS, Kim HT, Park JY, Lee KU, Jang WG, Kim JG, Kim BW, Lee IK (2007) Effects of PGC-1alpha on TNF-alpha-induced MCP-1 and VCAM-1 expression and NF-kappaB activation in human aortic smooth muscle and endothelial cells. Antioxid Redox Signal 9:301-307. https://doi.org/10.1089/ars.2006.1456

19. Pereira CD, Severo M, Neves D, Ascensao A, Magalhaes J, Guimaraes JT, Monteiro R, Martins MJ (2015) Natural mineral-rich water ingestion improves hepatic and fat glucocorticoid-signaling and increases sirtuin 1 in an animal model of metabolic syndrome. Horm Mol Biol Clin Investig 21:149-157. https:// doi.org/10.1515/hmbci-2014-0032

20. Caton PW, Nayuni NK, Khan NQ, Wood EG, Corder R (2011) Fructose induces gluconeogenesis and lipogenesis through a SIRT1-dependent mechanism. J Endocrinol 208:273-283. https ://doi.org/10.1530/JOE-10-0190

21. McBurney MW, Clark-Knowles KV, Caron AZ, Gray DA (2013) SIRT1 is a highly networked protein that mediates the adaptation to chronic physiological stress. Genes Cancer 4:125-134. https://doi.org/10.1177/1947601912474893

22. de Sousa Rodrigues ME, Bekhbat M, Houser MC, Chang J, Walker DI, Jones DP, Oller do Nascimento CM, Barnum CJ, Tansey MG (2017) Chronic psychological stress and high-fat high-fructose diet disrupt metabolic and inflammatory gene networks in the brain, liver, and gut and promote behavioral deficits in mice. Brain Behav Immun 59:158-172. https://doi. org/10.1016/j.bbi.2016.08.021

23. Kiecolt-Glaser JK (2010) Stress, food, and inflammation: psychoneuroimmunology and nutrition at the cutting edge. Psychosom Med 72:365-369. https://doi.org/10.1097/PSY.0b013e3181 dbf 489

24. Ventura EE, Davis JN, Goran MI (2011) Sugar content of popular sweetened beverages based on objective laboratory analysis: focus on fructose content. Obesity 19:868-874. https://doi. org/10.1038/oby.2010.255

25. Joels M, Karst H, Alfarez D, Heine VM, Qin Y, van Riel E, Verkuyl M, Lucassen PJ, Krugers HJ (2004) Effects of chronic stress on structure and cell function in rat hippocampus and hypothalamus. Stress 7:221-231. https://doi.org/10.1080/10253 890500070005

26. Velickovic N, Djordjevic A, Vasiljevic A, Bursac B, Milutinovic DV, Matic G (2013) Tissue-specific regulation of inflammation by macrophage migration inhibitory factor and glucocorticoids in fructose-fed Wistar rats. Br J Nutr 110:456-465. https://doi. org/10.1017/S0007114512005193

27. Vasiljevic A, Velickovic N, Bursac B, Djordjevic A, Milutinovic DV, Nestorovic N, Matic G (2013) Enhanced prereceptor glucocorticoid metabolism and lipogenesis impair insulin signaling in the liver of fructose-fed rats. J Nutr Biochem 24:1790-1797. https://doi.org/10.1016/j.jnutbio.2013.04.001

28. Folch J, Lees M, Sloane Stanley GH (1957) A simple method for the isolation and purification of total lipides from animal tissues. J Biol Chem 226:497-509

29. Glaser C, Demmelmair H, Koletzko B (2010) High-throughput analysis of total plasma fatty acid composition with direct in situ transesterification. PLoS One 5:e12045. https://doi.org/10.1371/ journal.pone.0012045

30. Petrovic S, Arsic A, Glibetic M, Cikiriz N, Jakovljevic V, Vucic V (2016) The effects of polyphenol-rich chokeberry juice on fatty acid profiles and lipid peroxidation of active handball players: results from a randomized, double-blind, placebo-controlled study. Can J Physiol Pharmacol 94:1058-1063. https://doi.org/10.1139/ cjpp-2015-0575

31. Spector T (1978) Refinement of the coomassie blue method of protein quantitation. A simple and linear spectrophotometric assay for less than or equal to 0.5 to 50 microgram of protein. Anal Biochem 86:142-146

32. Lira FS, Rosa JC, Yamashita AS, Koyama CH, Batista ML Jr, Seelaender M (2009) Endurance training induces depot-specific changes in IL-10/TNF-alpha ratio in rat adipose tissue. Cytokine 45:80-85. https://doi.org/10.1016/j.cyto.2008.10.018

33. Borovikova LV, Ivanova S, Zhang M, Yang H, Botchkina GI, Watkins LR, Wang H, Abumrad N, Eaton JW, Tracey KJ (2000) Vagus nerve stimulation attenuates the systemic inflammatory response to endotoxin. Nature 405:458-462. https://doi.org/10.1038/35013 070

34. Livak KJ, Schmittgen TD (2001) Analysis of relative gene expression data using real-time quantitative PCR and the 2(T)(-Delta Delta C) method. Methods 25:402-408. https://doi.org/10.1006/ meth.2001.1262 doi

35. Havel PJ (2005) Dietary fructose: implications for dysregulation of energy homeostasis and lipid/carbohydrate metabolism. Nutr Rev 63:133-157

36. Axelsen LN, Lademann JB, Petersen JS, Holstein-Rathlou NH, Ploug T, Prats C, Pedersen HD, Kjolbye AL (2010) Cardiac and metabolic changes in long-term high fructose-fat fed rats with severe obesity and extensive intramyocardial lipid accumulation. Am J Physiol Regul Integr Comp Physiol 298:R1560-R1570. https://doi.org/10.1152/ajpregu.00392.2009

37. Kawasaki T, Igarashi K, Koeda T, Sugimoto K, Nakagawa K, Hayashi S, Yamaji R, Inui H, Fukusato T, Yamanouchi T (2009) Rats fed fructose-enriched diets have characteristics of nonalcoholic hepatic steatosis. J Nutr 139:2067-2071. https://doi. org/10.3945/jn.109.105858

38. Lima ML, Leite LH, Gioda CR, Leme FO, Couto CA, Coimbra CC, Leite VH, Ferrari TC (2016) A novel Wistar rat model of obesity-related nonalcoholic fatty liver disease induced by sucrose-rich diet. J Diabetes Res 2016:9127076. https://doi. org/10.1155/2016/9127076

39. Tranchida F, Rakotoniaina Z, Shintu L, Tchiakpe L, Deyris V, Yemloul M, Stocker P, Vidal N, Rimet O, Hiol A, Caldarelli S (2017) Hepatic metabolic effects of Curcuma longa extract supplement in high-fructose and saturated fat fed rats. Sci Rep 7:5880. https://doi.org/10.1038/s41598-017-06220-0

40. Baena M, Sanguesa G, Davalos A, Latasa MJ, Sala-Vila A, Sanchez RM, Roglans N, Laguna JC, Alegret M (2016) Fructose, but not glucose, impairs insulin signaling in the three major insulin-sensitive tissues. Sci Rep 6:26149. https://doi.org/10.1038/ srep26149

41. Softic S, Gupta MK, Wang GX, Fujisaka S, O’Neill BT, Rao TN, Willoughby J, Harbison C, Fitzgerald K, Ilkayeva O, Newgard CB, Cohen DE, Kahn CR (2017) Divergent effects of glucose and fructose on hepatic lipogenesis and insulin signaling. J Clin Invest 127:4059-4074. https://doi.org/10.1172/JCI94585 
42. Monteiro S, Roque S, de Sa-Calcada D, Sousa N, Correia-Neves M, Cerqueira JJ (2015) An efficient chronic unpredictable stress protocol to induce stress-related responses in C57BL/6 mice. Front Psychiatry 6:6. https://doi.org/10.3389/fpsyt.2015.00006

43. Macedo IC, Medeiros LF, Oliveira C, Oliveira CM, Rozisky JR, Scarabelot VL, Souza A, Silva FR, Santos VS, Cioato SG, Caumo W, Torres IL (2012) Cafeteria diet-induced obesity plus chronic stress alter serum leptin levels. Peptides 38:189-196. https://doi. org/10.1016/j.peptides.2012.08.007

44. Bursac BN, Djordjevic AD, Vasiljevic AD, Milutinovic DD, Velickovic NA, Nestorovic NM, Matic GM (2013) Fructose consumption enhances glucocorticoid action in rat visceral adipose tissue. J Nutr Biochem 24:1166-1172. https://doi.org/10.1016/j. jnutbio.2012.09.002

45. Thompson AK, Fourman S, Packard AE, Egan AE, Ryan KK, Ulrich-Lai YM (2015) Metabolic consequences of chronic intermittent mild stress exposure. Physiol Behav 150:24-30. https:// doi.org/10.1016/j.physbeh.2015.02.038

46. Lozano I, Van der Werf R, Bietiger W, Seyfritz E, Peronet C, Pinget M, Jeandidier N, Maillard E, Marchioni E, Sigrist S, Dal S (2016) High-fructose and high-fat diet-induced disorders in rats: impact on diabetes risk, hepatic and vascular complications. Nutr Metab (Lond) 13:15. https://doi.org/10.1186/s12986-016-0074-1

47. Pang J, Xi C, Huang X, Cui J, Gong H, Zhang T (2016) Effects of excess energy intake on glucose and lipid metabolism in C57BL/6 mice. PLoS One 11:e0146675. https://doi.org/10.1371/journ al.pone. 0146675

48. Packard AE, Ghosal S, Herman JP, Woods SC, Ulrich-Lai YM (2014) Chronic variable stress improves glucose tolerance in rats with sucrose-induced prediabetes. Psychoneuroendocrinology 47:178-188. https://doi.org/10.1016/j.psyneuen.2014.05.016

49. Sanguesa G, Baena M, Hutter N, Montanes JC, Sanchez RM, Roglans N, Laguna JC, Alegret M (2017) The addition of liquid fructose to a western-type diet in LDL- $\mathrm{R}^{-1-}$ mice induces liver inflammation and fibrogenesis markers without disrupting insulin receptor signalling after an insulin challenge. Nutrients. https:// doi.org/10.3390/nu9030278

50. Vasiljevic A, Bursac B, Djordjevic A, Milutinovic DV, Nikolic M, Matic G, Velickovic N (2014) Hepatic inflammation induced by high-fructose diet is associated with altered 11betaHSD1 expression in the liver of Wistar rats. Eur J Nutr 53:1393-1402. https:// doi.org/10.1007/s00394-013-0641-4

51. Solinas G, Karin M (2010) JNK1 and IKKbeta: molecular links between obesity and metabolic dysfunction. FASEB J 24:25962611. https://doi.org/10.1096/fj.09-151340

52. Roglans N, Vila L, Farre M, Alegret M, Sanchez RM, VazquezCarrera M, Laguna JC (2007) Impairment of hepatic Stat-3 activation and reduction of PPARalpha activity in fructose-fed rats. Hepatology 45:778-788. https://doi.org/10.1002/hep.21499

53. Chen Z, Yu R, Xiong Y, Du F, Zhu S (2017) A vicious circle between insulin resistance and inflammation in nonalcoholic fatty liver disease. Lipids Health Dis 16:203. https://doi.org/10.1186/ s12944-017-0572-9

54. Gauthier MS, O'Brien EL, Bigornia S, Mott M, Cacicedo JM, Xu XJ, Gokce N, Apovian C, Ruderman N (2011) Decreased AMPactivated protein kinase activity is associated with increased inflammation in visceral adipose tissue and with whole-body insulin resistance in morbidly obese humans. Biochem Biophys Res Commun 404:382-387. https://doi.org/10.1016/j. bbrc.2010.11.127

55. Liu Q, Gauthier MS, Sun L, Ruderman N, Lodish H (2010) Activation of AMP-activated protein kinase signaling pathway by adiponectin and insulin in mouse adipocytes: requirement of acyl-CoA synthetases FATP1 and Acs11 and association with an elevation in AMP/ATP ratio. FASEB J 24:4229-4239. https://doi. org/10.1096/fj.10-159723
56. Chen HL, Tsai TC, Tsai YC, Liao JW, Yen CC, Chen CM (2016) Kefir peptides prevent high-fructose corn syrup-induced nonalcoholic fatty liver disease in a murine model by modulation of inflammation and the JAK2 signaling pathway. Nutr Diabetes 6:e237. https://doi.org/10.1038/nutd.2016.49

57. Andrade J, Quinn J, Becker RZ, Shupnik MA (2013) AMP-activated protein kinase is a key intermediary in GnRH-stimulated LHbeta gene transcription. Mol Endocrinol 27:828-839. https:// doi.org/10.1210/me.2012-1323

58. Beauloye C, Marsin AS, Bertrand L, Krause U, Hardie DG, Vanoverschelde JL, Hue L (2001) Insulin antagonizes AMP-activated protein kinase activation by ischemia or anoxia in rat hearts, without affecting total adenine nucleotides. FEBS Lett 505:348-352

59. Gugliucci A (2016) Fructose surges damage hepatic adenosylmonophosphate-dependent kinase and lead to increased lipogenesis and hepatic insulin resistance. Med Hypotheses 93:87-92. https://doi.org/10.1016/j.mehy.2016.05.026

60. Cao X, Miner JN, Terkeltaub R, Liu-Bryan R (2016) Fructose amplifies inflammatory potential in human monocytic cells via reduction of AMP-activated protein kinase activity. Arthritis Rheumatol 68(suppl 10):Abstract 2268

61. Lambertz J, Weiskirchen S, Landert S, Weiskirchen R (2017) Fructose: a dietary sugar in crosstalk with microbiota contributing to the development and progression of non-alcoholic liver disease. Front Immunol 8:1159. https://doi.org/10.3389/fimmu .2017 .01159

62. Wagnerberger S, Spruss A, Kanuri G, Volynets V, Stahl C, Bischoff SC, Bergheim I (2012) Toll-like receptors 1-9 are elevated in livers with fructose-induced hepatic steatosis. Br J Nutr 107:1727-1738. https://doi.org/10.1017/S0007114511004983

63. Zhang X, Zhang JH, Chen XY, Hu QH, Wang MX, Jin R, Zhang QY, Wang W, Wang R, Kang LL, Li JS, Li M, Pan Y, Huang JJ, Kong LD (2015) Reactive oxygen species-induced TXNIP drives fructose-mediated hepatic inflammation and lipid accumulation through NLRP3 inflammasome activation. Antioxid Redox Signal 22:848-870. https://doi.org/10.1089/ars.2014.5868

64. Bursać B, Djordjevic A, Veličković N, Milutinović D, Petrović S, Teofilović A, Gligorovska L, Preitner F, Tappy L, Matić G (2018) Involvement of glucocorticoid prereceptor metabolism and signaling in rat visceral adipose tissue lipid metabolism after chronic stress combined with high-fructose diet. Mol Cell Endocrinol. https://doi.org/10.1016/j.mce.2018.04.015

65. Sharifnia T, Antoun J, Verriere TG, Suarez G, Wattacheril J, Wilson KT, Peek RM Jr, Abumrad NN, Flynn CR (2015) Hepatic TLR4 signaling in obese NAFLD. Am J Physiol Gastrointest Liver Physiol 309:G270-G278. https://doi.org/10.1152/ajpgi.00304 .2014

66. Zhang Y, Woodruff M, Zhang Y, Miao J, Hanley G, Stuart C, Zeng X, Prabhakar S, Moorman J, Zhao B, Yin D (2008) Toll-like receptor 4 mediates chronic restraint stress-induced immune suppression. J Neuroimmunol 194:115-122. https://doi.org/10.1016/j. jneuroim.2007.12.002

67. Dittrich A, Khouri C, Sackett SD, Ehlting C, Bohmer O, Albrecht U, Bode JG, Trautwein C, Schaper F (2012) Glucocorticoids increase interleukin-6-dependent gene induction by interfering with the expression of the suppressor of cytokine signaling 3 feedback inhibitor. Hepatology 55:256-266. https://doi.org/10.1002/ hep. 24655

68. Schmidt-Arras D, Rose-John S (2016) IL-6 pathway in the liver: from physiopathology to therapy. J Hepatol 64:1403-1415. https ://doi.org/10.1016/j.jhep.2016.02.004

69. Leclercq IA, Lebrun VA, Starkel P, Horsmans YJ (2007) Intrahepatic insulin resistance in a murine model of steatohepatitis: effect of PPARgamma agonist pioglitazone. Lab Investig J Tech Methods Pathol 87:56-65. https://doi.org/10.1038/labinvest.37004 89 
70. McKay LI, Cidlowski JA (1999) Molecular control of immune/ inflammatory responses: interactions between nuclear factorkappa B and steroid receptor-signaling pathways. Endocr Rev 20:435-459. https://doi.org/10.1210/edrv.20.4.0375

71. Miao H, Zhang Y, Lu Z, Liu Q, Gan L (2012) FOXO1 involvement in insulin resistance-related pro-inflammatory cytokine production in hepatocytes. Inflamm Res 61:349-358. https://doi.org/10.1007/ s00011-011-0417-3

72. Koo HY, Miyashita M, Cho BH, Nakamura MT (2009) Replacing dietary glucose with fructose increases ChREBP activity and SREBP-1 protein in rat liver nucleus. Biochem Biophys Res Commun 390:285-289. https://doi.org/10.1016/j.bbrc.2009.09.109 